\title{
LA ALTA NOBLEZA Y EL PODER EN EL ESTADO DURANTE EL ANTIGUO RÉGIMEN (SIGLOS XVI-XVIII): UN BALANCE CUANTITATIVO
}

\author{
Pedro Luis Lorenzo Cadarso \\ Universidad de Extremadura
}

RESUMEN: Este artículo estudia la evolución de la presencia de la nobleza titulada en los distintos ámbitos de poder estatal durante los siglos XVI al XVIII, comparándola con la de los otros colectivos sociales que aspiraban también a ocupar cargos relevantes. Se hace desde una perspectiva estrictamente cuantitativa, al objeto de permitir evaluar la magnitud de los fenómenos que se describen y elaborar una cronología precisa de los mismos.

Palabras clave: Nobleza, burocracia, Historia Moderna de España, Historia de las Instituciones, Historia Social.

\section{THE NOBILITY AND THE POWER IN THE STATE DURING THE OLD REGIME (XVI-XVIII CENTURIES): A QUANTITATIVE BALANCE}

ABSTRACT: This article studies the evolution of the presence of the titled nobility in the various areas of state power during the sixteenth and eighteenth centuries, comparing it with that of other social groups that also aspired to occupy significant positions. It is made from a strictly quantitative perspective, in order to allow assessment of the magnitude of the phenomena described and develop a precise chronology of the same.

Keywords: Nobility, bureaucracy, Modern History of Spain, History of the Institutions, Social History. 
Los estudios sobre élites sociales y políticas, y especialmente los dedicados a la nobleza, han sido muy numerosos en las últimas décadas y generado interesantes debates sobre los procesos sociales subyacentes, fundamentalmente, una reordenación de las estructuras internas de las élites españolas y, posiblemente, un proceso de refeudalización. El presente trabajo pretende hacer una aportación humilde, pero que considero necesaria: cuantificar dicho proceso en su ámbito burocrático-estatal. El problema que existe al día de hoy es que el enorme volumen de información empírica que se ha acumulado durante varias décadas de investigación sobre la historia social de la Administración se encuentra disperso y ello dificulta la elaboración de conclusiones sostenidas sobre bases científicamente sólidas.

Pero esa información existe y ha sido publicada, de modo que hoy podemos identificar con bastante exactitud a buena parte de los altos funcionarios del Estado durante la Edad Moderna, algo que hace unas décadas era impensable. En el recorrido cuantitativo que vamos a realizar se procede a clasificar al personal burocrátiCo -o a una parte de él- en cinco grandes grupos: clérigos, alta nobleza, militares, burócratas y élites locales. Son, como es sabido, los grupos sociales de donde se extraían al grueso de los altos funcionarios del Estado y entre ellos se establecerán pugnas y colaboraciones que irán más allá de la lucha por el poder, pues terminaron implicando debates en torno al valor del mérito de las armas frente al de las letras o al valor de la sangre heredada frente al de los méritos personales.

En total han sido computadas 10.872 designaciones de altos cargos -incluyendo los títulos nobiliarios-, a los que hay que sumar la información sobre los corregidores castellanos, los caballeros de las Órdenes Militares, los estudiantes universitarios y sobre algunos militares borbónicos, que aprovecho de diversos autores sin reelaborarla. La información disponible se clasifica en un total de 59 cuadros estadísticos. La muestra, por supuesto, no es exhaustiva, pero creo que tiene la suficiente magnitud como para resultar significativa. Los individuos designados que no han podido ser identificados son un porcentaje muy pequeño en la mayoría de los ámbitos, pues los porcentajes más elevados de no identificados son los gobernadores de plazas africanas -con un 6\%-y los de Indias -con un 4\%-.

El concepto "alto cargo del Estado" es también relativamente confuso y yo lo he aplicado además de forma muy selectiva, pues tan sólo he considerado como tales a los puestos unipersonales de gobierno, no a los colegiados. Tampoco he tomado en consideración algunos cargos importantes, pero cuyo acceso estaba reservado a un determinado colectivo, como por ejemplo las regencias de las audiencias, que tenían que ser ocupadas necesariamente por oidores, o las secretarías de los Austrias, que sólo eran ejercidas por burócratas. Lo mismo ocurre con cargos como el de "Confesor Real", que necesariamente era un clérigo, o con la mayoría de los altos cargos de la Casa del Rey, que eran ejercidos por nobles titulados tradicionalmente. Al tener estos requisitos, estudiar este tipo 
de puestos no nos hubiese aportado ninguna luz sobre el proceso social al que hacíamos referencia al principio.

Otro problema todavía más grave es que utilizar un enfoque estrictamente jurídico-institucional implica soslayar las redes clientelares que subyacen al ejercicio del poder y al reparto de los cargos públicos ${ }^{1}$, la venalidad de los oficios como factor distorsionador ${ }^{2}$ y la existencia de núcleos de influencia que no necesariamente tenían una concreción institucional ${ }^{3}$, fenómenos que en un estudio global deberían jugar un papel interpretativo central.

Nuestro objetivo es cuantificar, sólo en su vertiente institucional, el auge y declive de un colectivo social que protagonizó el Antiguo Régimen: la alta nobleza. El Absolutismo exigió a este grupo una reconversión profunda para adaptarse a los nuevos centros y formas de poder e influencia, y en la primera fase de construcción del Estado Absoluto tuvieron dificultades evidentes y ya conocidas, pero a lo largo del siglo XVII su presencia en los centros de poder, como veremos, no dejará de aumentar, Ilegando a máximos históricos durante el reinado del Carlos II, momento en el que, paradójicamente, dejaron de controlar las vías de ascenso social que permitían acceder a sus filas -las mercedes de títulos por el rey- y a partir de entonces su participación en el poder no hizo sino reducirse paulatinamente. La política de profesionalización del ejército y de la burocracia seguida por los Borbones terminó también por convertirse en una trava para muchos nobles cuyos "méritos" no iban más allá de sus apellidos. Es, por tanto, muy complicado hablar de refeudalización en el núcleo del Estado durante el siglo XVII, pues resulta evidente que éste generó desde muy temprano sus propias dinámicas internas -tanto en términos hacendísticos, como político- jurisdiccionales e incluso intelectuales- , que los grandes linajes nobiliarios no consiguieron nunca controlar por completo, ni siquiera en el siglo XVII, cuando objetivamente aumentó su capacidad de presión y su presencia en los órganos decisorios ${ }^{4}$. Ya en el siglo XVIII estamos ante un grupo social en declive, por mucho que determinados linajes sigan siendo inmensamente ricos y muy influyentes.

1. Un repaso a este fenómeno en FEROS, A., "Clientelismo y poder monárquico en la España de los siglos XVI y XVII", Relaciones, no 19 (73), 1998, pp. 17-49.

2. Un repaso a este asunto en JIMÉNEZ ESTRELLA, A., "Poder, dinero y ventas de oficios y honores en la España del Antiguo Régimen: un estado de la cuestión", Cuadernos de Historia Moderna, 2012, 37, 259-272.

3. Véanse, por ejemplo, los trabajos de MOLINA PUCHE, S., como "Más allá del concejo. Sobre élites locales a través del ejemplo del corregimiento de Chinchilla en el siglo XVII", Revista de Historia Social y de las Mentalidades, No XI, Vol. 2, 2007, pp. 15-38.

4. Véanse las reflexiones que sobre este concepto hace GARCíA MARÍN, J. M., en "En torno a la naturaleza del poder real en la Monarquía de los Austrias", Historia, Instituciones y Documentos, $\mathrm{n}^{\circ} 11,1984$, pp. 115-156. 
La primera cuestión a abordar es su número. Partiendo de unas magnitudes realmente exiguas -en 1500 había en España 141 títulos nobiliarios reconocidos-, en 1799 se superaron los 1.700 títulos, un crecimiento del 1.200\%:

TABLA 1. Concesión de títulos nobiliarios por periodos (valores acumulados hasta 1799).

\begin{tabular}{|l|c|c|c|}
\hline \multicolumn{1}{|c|}{ PERIODO } & CONCEDIDOS & ACUMULADOS & \% VARIACIÓN \\
\hline Anteriores a 1500 & 141 & 141 & - \\
\hline $1500-1519$ & 17 & 158 & $+12 \%$ \\
\hline $1520-1539$ & 30 & 188 & $+19 \%$ \\
\hline $1540-1559$ & 22 & 210 & $+12 \%$ \\
\hline $1560-1579$ & 25 & 235 & $+12 \%$ \\
\hline $1580-1599$ & 34 & 269 & $+14 \%$ \\
\hline Siglo XVI & $\mathbf{1 2 8}$ & $\mathbf{2 6 9}$ & $+\mathbf{1 9 0} \%$ \\
\hline $1600-1619$ & 82 & 351 & $+30 \%$ \\
\hline $1620-1639$ & 148 & 499 & $+42 \%$ \\
\hline $1640-1659$ & 95 & 594 & $+19 \%$ \\
\hline $1660-1679$ & 108 & 702 & $+18 \%$ \\
\hline $1680-1699$ & 283 & 985 & $+40 \%$ \\
\hline Siglo XVII & $\mathbf{7 1 6}$ & $\mathbf{9 8 5}$ & $+\mathbf{3 3 9} \%$ \\
\hline $1700-1719$ & 211 & 1.196 & $+21 \%$ \\
\hline $1720-1739$ & 87 & 1.283 & $+7 \%$ \\
\hline $1740-1759$ & 77 & 1.360 & $+6 \%$ \\
\hline $1760-1779$ & 185 & 1.545 & $+14 \%$ \\
\hline $1780-1799$ & 162 & 1.707 & $+10 \%$ \\
\hline Siglo XVIII & $\mathbf{7 2 2}$ & $\mathbf{1 . 7 0 7}$ & $+\mathbf{1 7 3}$ \\
\hline Total 1500-1799 & $\mathbf{1 . 5 6 6}$ & $\mathbf{1 . 7 0 7}$ & $+\mathbf{1 . 2 1 0} \%$ \\
\hline
\end{tabular}

La Ilamada "inflación de títulos" tiene sus ritmos: Carlos I y Felipe II fueron parcos en la concesión de mercedes de este tipo: algo más de 100 en casi un siglo, nada en comparación con lo que se avecinaba: Felipe III concedió en 20 años 114, casi tantas como su padre, su abuelo y su bisabuela juntos. Pero el gran cambio se produciría a partir del reinado de Felipe IV, cuando se puso en marcha un plan de venta masiva de títulos por la Hacienda Real, lo que generó 631 nuevos nobles en las décadas siguientes, una tasa crecimiento que no se superaría hasta los reinados de Amadeo de Saboya y Alfonso XII ${ }^{5}$. Durante el

5. Véase: RODRíGUEZ HERNÁNDEZ, A. J., "La creación de Títulos de Castilla durante los reinados de Felipe IV y Carlos II: concesiones y ritmos", en DÍAZ LÓPEZ, J. P. et al. (eds.), 
siglo XVIII, aunque nunca se alcanzaron los niveles de finales del XVII, se continuaron concediendo títulos con profusión, contribuyendo así a su paulatina devaluación, incluso económica, pues un título costaba más a mediados del XVII que a finales del XVIII.

TABLA 2. Títulos nobiliarios concedidos por reinados.

\begin{tabular}{|c|c|c|}
\hline MONARCAS & $\begin{array}{c}\mathbf{N}^{\mathbf{o}} \\
\text { DE TÍTULOS }\end{array}$ & $\begin{array}{c}\text { RATIO TÍTULOS/ } \\
\text { A Ñ̃ } \\
\end{array}$ \\
\hline Reyes Católicos (1474-1504) & 56 & 1,8 \\
\hline Juana I (1504-1516) & 6 & 0,5 \\
\hline Carlos I (1516-1556) & 50 & 1,2 \\
\hline Felipe II (1556-1598) & 64 & 2 \\
\hline Felipe III (1598-1621) & 114 & 4,9 \\
\hline Felipe IV (1621-1665) & 268 & 6,1 \\
\hline Carlos II (1665-1700) & $363^{1}$ & 10,4 \\
\hline Carlos VI (Habsburgo) (1703-1715) & $46^{2}$ & 3,8 \\
\hline Felipe V (1700-1746) & 255 & 5,5 \\
\hline Fernando VI (1746-1759) & 57 & 4,3 \\
\hline Carlos III (1759-1788) & 224 & 5,7 \\
\hline Carlos IV (1788-1808) & 152 & 7,6 \\
\hline Fernando VII (1813-1833) & 102 & 5,1 \\
\hline Carlos María Isidro (1833-1839) & $7^{3}$ & 1,1 \\
\hline Isabel II (1833-1868) & $238^{4}$ & 6,8 \\
\hline Amadeo I (1870-1873) & 57 & 19 \\
\hline Alfonso XII (1874-1885) & 152 & 13,8 \\
\hline Alfonso XIII (1886-1931) & $345^{5}$ & 9,8 \\
\hline Francisco Franco (1936-1975) & 37 & 0,9 \\
\hline Juan Carlos I (1975-2014) & 47 & 1,2 \\
\hline
\end{tabular}

1. 2 fueron concedidos por la Regente Mariana de Austria.

2. 26 fueron concedidos siendo ya Emperador. Estos títulos fueron reconocidos luego por el Rey de España.

3. Los títulos fueron reconocidos posteriormente por el Rey de España.

4. 26 títulos fueron concedidos por la Regente María Cristina de Borbón.

5. 139 fueron concedidos por la Regente María Cristina de Habsburgo.

Casas, Familias y Rentas. La nobleza del Reino de Granada entre los siglos XV-XVIII, Granada, 2010, pp. 167 y ss. 
Pero un interés todavía mayor tiene analizar el origen social de quienes accedieron a las filas de la alta nobleza. Se puede observar como, hasta el reinado de Carlos II, son los segundones de los viejos linajes heredados de la Edad Media quienes controlan el acceso a los nuevos títulos: un $80 \%$ de ellos son hijos o nietos de nobles titulados, y si utilizásemos de forma más laxa el concepto de "linaje", el porcentaje aumentaría muy significativamente. A partir de 1660 ese porcentaje se reduce hasta el $38 \%$ y caerá por debajo del $20 \%$ en el siglo XVIII, esto es, que de los 1.095 receptores de títulos durante esta fase, sólo 241 eran hijos o nietos de nobles titulados. Los principales beneficiarios de este cambio fueron los miembros de las élites locales, que pasaron de suponer un $6 \%$ de los títulos en los siglos XVI y XVII a un $38 \%$ en el periodo siguiente. La caída de la participación de la nobleza titulada en las nuevas concesiones es especialmente significativa si tenemos en cuenta que hacia 1700 había nueve veces más nobles titulados que al comienzo del periodo, esto es, un 927\% de potenciales receptores más que en 1500.

TABLA 3. Origen social de los receptores de títulos nobiliarios.

\begin{tabular}{|c|c|c|c|c|c|c|c|c|}
\hline \multirow[t]{2}{*}{ Periodo } & \multicolumn{2}{|c|}{$\begin{array}{c}\text { ÉLITES } \\
\text { LOCALES }\end{array}$} & \multicolumn{2}{|c|}{ BUROCRACIA } & \multicolumn{2}{|c|}{ MILITARES } & \multicolumn{2}{|c|}{$\begin{array}{c}\text { ALTA } \\
\text { NOBLEZA }\end{array}$} \\
\hline & $\mathbf{N}^{\mathbf{o}}$ & $\%$ & $N^{o}$ & $\%$ & $\mathbf{N}^{0}$ & $\%$ & $N^{o}$ & $\%$ \\
\hline $1500-1519$ & 0 & 0 & 0 & 0 & 0 & 0 & 16 & 100 \\
\hline 1520-1539 & 1 & 3 & 2 & 6 & 2 & 6 & 27 & 85 \\
\hline 1540-1559 & 1 & 5 & 2 & 9 & 1 & 5 & 17 & 81 \\
\hline 1560-1579 & 0 & 0 & 4 & 16 & 2 & 8 & 19 & 76 \\
\hline 1580-1599 & 0 & 0 & 1 & 3 & 2 & 6 & 32 & 91 \\
\hline 1600-1619 & 2 & 2 & 8 & 10 & 4 & 5 & 66 & 83 \\
\hline 1620-1639 & 16 & 11 & 18 & 12 & 11 & 7 & 93 & 70 \\
\hline $1640-1659$ & 10 & 7 & 7 & 5 & 11 & 8 & 105 & 80 \\
\hline Periodo 1500-1659 & 30 & 6 & 42 & 9 & 33 & 7 & 375 & 78 \\
\hline $1660-1679$ & 22 & 22 & 18 & 18 & 21 & 21 & 38 & 38 \\
\hline 1680-1699 & 96 & 35 & 59 & 22 & 48 & 18 & 69 & 25 \\
\hline 1700-1719 & 61 & 30 & 42 & 21 & 36 & 18 & 63 & 31 \\
\hline 1720-1739 & 27 & 31 & 29 & 33 & 21 & 24 & 10 & 11 \\
\hline 1740-1759 & 25 & 35 & 17 & 24 & 19 & 26 & 11 & 15 \\
\hline $1760-1779$ & 117 & 55 & 41 & 19 & 30 & 14 & 26 & 12 \\
\hline $1780-1799$ & 70 & 47 & 29 & 19 & 26 & 17 & 24 & 16 \\
\hline Periodo 1660-1799 & 418 & 38 & 235 & 21 & 201 & 18 & 241 & 22 \\
\hline TOTAL & 448 & 29 & 277 & 18 & 234 & 15 & 606 & 39 \\
\hline
\end{tabular}

1. Se han consignado como tales a los hijos y nietos de nobles titulados. 
Contra lo que podría pensarse, el acceso masivo a la nobleza titulada de las élites locales y de los servidores del rey a partir de finales del siglo XVII -éstos últimos, militares o burócratas, multiplicarán por más de dos su participación en las mercedes- no tuvo su principal causa en la aparición de cambios sociales profundos de tipo estructural, en realidad fue una cuestión política, o más concretamente hacendística: fue la necesidad de dinero de la Hacienda Real la que abrió las puertas a este fenómeno. En las dignidades nobiliarias que no fueron venales, la situación evolucionó de forma significativamente distinta: se concedieron muy pocas y de forma muy selectiva. Contrasta, por ejemplo, las poquísimas grandezas de España que concedieron los Austrias: 58 frente a 859 títulos nobiliarios, un 6\%. Además, los principales beneficiarios de las grandezas de España fueron los linajes de origen bajomedieval, especialmente en los siglos XVI y XVII -un $84 \%$ de las concedidas, que en el XVIII se reducirán, pero conservando un relevante $58 \%{ }^{-}$.

TABLA 4. Origen familiar de los grandes de España ${ }^{6}$.

\begin{tabular}{|l|c|c|c|c|}
\hline \multirow{2}{*}{ Reinado } & \multicolumn{2}{|c|}{ LINAJES MEDIEVALES } & \multicolumn{2}{c|}{ NUEVA NOBLEZA } \\
\cline { 2 - 5 } & $\mathbf{N}^{\mathbf{0}}$ & $\mathbf{\%}$ & $\mathbf{N}^{\mathbf{0}}$ & $\mathbf{\%}$ \\
\hline 1500-1515 & 4 & 100 & 0 & 0 \\
\hline Carlos I & 4 & 80 & 1 & 20 \\
\hline Felipe II & 7 & 100 & 0 & 0 \\
\hline Felipe III & 7 & 78 & 2 & 22 \\
\hline Felipe IV & 17 & 89 & 2 & 11 \\
\hline Carlos II & 10 & 71 & 4 & 29 \\
\hline Felipe V & 35 & 61 & 22 & 39 \\
\hline Fernando VI & 1 & 50 & 1 & 50 \\
\hline Carlos III & 20 & 66 & 10 & 33 \\
\hline 1789-1799 & 6 & 23 & 12 & 67 \\
\hline TOTAL & $\mathbf{1 1 1}$ & $\mathbf{6 7}$ & $\mathbf{5 4}$ & $\mathbf{3 3}$ \\
\hline
\end{tabular}

En cuanto a los méritos personales de servicio a la Corona que pudieron alegar los nobles agraciados con una Grandeza de España, hasta Carlos II un 60\% habían ejercido puestos de mando en el Ejército o la Administración, pero la pérdida de poder del colectivo provocó que en el XVIII sólo un 35\% estuvieran

6. Hasta Felipe II no aparecen las primeras concesiones expresas como "Grandes de España" y hasta Felipe IV no se formaliza esta categoría. Anteriores a 1500 fueron reconocidas un total de 27 grandezas de España. Una obra reciente sobre este colectivo: SALAZAR, J., Los grandes de España (siglos XV-XXI), Madrid, Hidalguía, 2012. 
en esa situación y en la segunda mitad del siglo el porcentaje se reduciría hasta el $28 \%$.

TABLA 5. Méritos de los grandes de España por reinados.

\begin{tabular}{|c|c|c|c|c|c|c|}
\hline \multirow{2}{*}{ Reinado } & \multicolumn{2}{|c|}{ SIN MÉRITOS ${ }^{1}$} & \multicolumn{2}{|c|}{$\begin{array}{c}\text { MÉRITOS } \\
\text { MILITARES }\end{array}$} & \multicolumn{2}{|c|}{$\begin{array}{l}\text { MÉRITOS } \\
\text { POLÍTICOS }\end{array}$} \\
\hline & $\mathrm{N}^{\mathbf{o}}$ & $\%$ & $\mathbf{N}^{\mathbf{o}}$ & $\%$ & $\mathrm{~N}^{\mathbf{o}}$ & $\%$ \\
\hline 1500-1515 & 0 & 0 & 4 & 100 & 0 & 0 \\
\hline Carlos I & 3 & 50 & 0 & 0 & 3 & 50 \\
\hline Felipe II & 2 & 25 & 1 & 12 & 5 & 62 \\
\hline Siglo XVI & 5 & 28 & 5 & 28 & 8 & 44 \\
\hline Felipe III & 4 & 44 & 1 & 12 & 4 & 44 \\
\hline Felipe IV & 11 & 50 & 4 & 18 & 7 & 32 \\
\hline Carlos II & 5 & 38 & 2 & 15 & 6 & 46 \\
\hline Siglo XVII & 20 & 45 & 7 & 16 & 17 & 39 \\
\hline Felipe V & 33 & 58 & 11 & 19 & 13 & 23 \\
\hline Fernando VI & 0 & 0 & 1 & 100 & 0 & 0 \\
\hline Carlos III & 24 & 75 & 5 & 16 & 3 & 9 \\
\hline 1789-1799 & 16 & 70 & 4 & 17 & 3 & 13 \\
\hline Siglo XVIII & 73 & 65 & 21 & 18 & 19 & 17 \\
\hline TOTAL & 98 & 56 & 33 & 19 & 44 & 25 \\
\hline
\end{tabular}

1. Se incluyen en este grupo los cargos cortesanos de la Casa Real.

¿Qué procesos imposibilitaron a la alta nobleza bajomedieval seguir controlando el acceso a sus filas? Uno de ellos pudo ser la venta de jurisdicciones señoriales por la Corona, un fenómeno que se desarrolló de forma paralela al aumento de nobles titulados y que ha sido interpretado de maneras contrapuestas: como un signo de señorialización o refeudalización y como una nueva vía de ascenso social. Los linajes de la alta nobleza no fueron los principales beneficiarios de estas enajenaciones, quizás por su más que delicada situación económica ${ }^{7}$, sino burócratas enriquecidos y miembros de las

7. Véase YUN CASALILLA, B., "La situación económica de la aristocracia castellana durante los reinados de Felipe III y Felipe IV", en La España del Conde-duque de Olivares, Valladolid, 1990, pp. 19-55. Entre los nobles titulados residentes en Lima, por ejemplo, según un informe del virrey fechado en 1700, de los 29 existentes, 9 fueron clasificados como "pobres" 
élites locales hidalgas. Ambos grupos conformaron así un numeroso colectivo de nobleza intermedia en condiciones de asimilarse a los viejos linajes medievales. Pero lo cierto es que la Corona no trató en ningún momento de promover la movilidad social ${ }^{8}$, incluso podríamos concluir que intentó evitarla aumentando los requisitos exigidos para ser reconocido como hidalgo en la Sala de Hijosdalgo de las Chancillerías ${ }^{9}$ e imponiendo investigaciones sobre los receptores de títulos nobiliarios, que debía realizar la Cámara de Castilla. Los nobles que accedían a títulos sin ser segundones de la alta nobleza era frecuente que tuviesen serias dificultades para superar esa investigación -habían de acreditar nobleza, limpieza de sangre, méritos personales y de sus antepasados y un nivel económico y un modo de vida que les permitiera llevar el título nobiliario con decoro-. Sin embargo, en la práctica, la Hacienda Real tenía otras prioridades y desde finales del XVII la mayoría de las mercedes suelen concederse mediante Real Decreto, eludiendo así la investigación de la Cámara de Castilla y sus previsibles consecuencias ${ }^{10}$. Y es que, contra lo que podría pensarse, la mayor parte de ellos no pertenecían a lo que se conoce como "nobleza intermedia", esto es, no eran señores de vasallos sin título nobiliario, pese al enorme volumen de poblaciones cuya jurisdicción se vendió durante los siglos XVI y XVIII ${ }^{11}$. Los señores de vasallos suponen hasta el siglo XVII en torno al $40 \%$ de los nuevos titulados, pero serán ya poco más del $10 \%$ en el XVIII.

o "muy pobres" y otros 6 como de ingresos insuficientes. Cfr. RIZO PATRÓN, P., "La nobleza de Lima en tiempo de los Borbones", Boletín del Instituto de Estudios Andinos, 1990, 19, ${ }^{\circ}$ 1, pp. 129-163.

8. Véanse los trabajos recogidos en GÓMEZ GONZÁLEZ, I. y LÓPEZ-GUADALUPE MUÑOZ, M. L. (coords.), La movilidad social en la España del Antiguo Régimen, Comares, 2007.

9. Véase el análisis de las Reales Cédulas de 1492, 1593 y 1625 en DOMÍNGUEZ ORTIZ, A., La sociedad española en el siglo XVII: El estamento nobiliario, Granada, 1992, p. 176.

10. Cfr. FELICES DE LA FUENTE, M. M., "la Cámara de Castilla, el rey y la creación de títulos nobiliarios en la primera mitad del siglo XVIII", HISPANIA. Revista Española de Historia, 2010, vol. LXX, núm. 236, pp. 661-686.

11. FAYA DÍAZ, M. A., "La venta de jurisdicciones eclesiásticas en la corona de Castilla durante el reinado de Felipe II", en Felipe II (1598-1998), Europa dividida, la monarquía católica de Felipe II, Madrid, Parteluz, 1998, pp. 239-303 (Tomo 2) y DOMíNGUEZ ORTIZ, A., "Ventas y exenciones de lugares durante el reinado de Felipe IV", Anuario de Historia del Derecho Español, XXXIV, 1964, pp. 164 y ss. A partir de los datos aportados en la primera de las obras citadas, de los 115 compradores privados de jurisdicciones durante el reinado de Felipe II, sólo 25 estaban vinculados a los linajes de la alta nobleza, es decir, un $22 \%$. 
Tabla 6. Señores de vasallos entre la nueva nobleza titulada.

\begin{tabular}{|c|c|c|c|c|}
\hline \multirow{2}{*}{ Reinado } & \multicolumn{2}{|c|}{ SEÑORES DE VASALLOS } & \multicolumn{2}{|c|}{$\begin{array}{c}\text { NO SEÑORES DE } \\
\text { VASALLOS }\end{array}$} \\
\hline & $N^{o}$ & $\%$ & $N^{o}$ & $\%$ \\
\hline Carlos I & 6 & 46 & 7 & 54 \\
\hline Felipe II & 2 & 29 & 5 & 71 \\
\hline Felipe III & 7 & 37 & 12 & 63 \\
\hline Felipe IV & 32 & 42 & 45 & 58 \\
\hline Carlos II & 106 & 40 & 158 & 60 \\
\hline Felipe V & 36 & 16 & 185 & 84 \\
\hline Fernando VI & 3 & 8 & 36 & 92 \\
\hline Carlos III & 24 & 13 & 161 & 87 \\
\hline 1789-1799 & 10 & 11 & 82 & 89 \\
\hline TOTAL & 226 & 25 & 691 & 75 \\
\hline
\end{tabular}

Otra barrera que se comenzó a derrumbar en el siglo XVII fue la de las restricciones que pesaban sobre los mercaderes, y ello tendría consecuencias importantes para la alta nobleza. El ejercicio de las actividades mercantiles había sido entendido tradicionalmente como incompatible con los reconocimientos nobiliarios más distinguidos, como las Órdenes Militares, y de hecho, las familias de mercaderes o banqueros que acceden a la nobleza titulada hasta el reinado de Felipe III son muy pocas y muy distinguidas, como los Centurione, los Santángel o los Juliá, que compaginaban las labores mercantiles con cargos políticos o que incluso habían abandonado totalmente las primeras antes de acceder al título ${ }^{12}$. Desde 1628, el gobierno del Conde-Duque trató de invertir esta situación, decretando que ser mercader no inhabilitaba para acceder a las Órdenes Militares ${ }^{13}$, inaugurándose así, aunque tímidamente, una tendencia al aumento de comerciantes entre los beneficiarios de títulos nobiliarios, quienes Ilegarán a ser casi el 20\% en el reinado de Carlos III.

12. Véase, por ejemplo, REIZABAL GARRIGOSA. M. S., "La familia valenciana de los Julia, de mercaderes a señores de la baronía de Benidoleig. 1565-1637", Estudis, 18, 1992, pp. 59-7.

13. DOMínGuEZ ORTIZ, A., "Comercio y blasones. Concesiones de hábitos de órdenes militares a miembros del consulado de Sevilla en el siglo XVII", Anuario de estudios americanos, $\mathrm{n}^{\circ} 33,1976$, pp. 217-256. 
TABLA 7. Concesión de títulos nobiliarios a comerciantes ${ }^{14}$.

\begin{tabular}{|l|c|c|c|}
\hline \multirow{2}{*}{\multicolumn{1}{c|}{ Reinado }} & \multirow{2}{*}{ TOTAL TítULOS } & \multicolumn{2}{c|}{ TíTULOS A COMERCIANTES } \\
\cline { 3 - 4 } & & $\mathbf{N}^{\mathbf{0}}$ & $\%$ \\
\hline Carlos I & 50 & 3 & 6 \\
\hline Felipe II & 64 & 1 & 2 \\
\hline Felipe III & 114 & 1 & 1 \\
\hline Felipe IV & 268 & 5 & 2 \\
\hline Carlos II & 363 & 24 & 7 \\
\hline Felipe V & 301 & 39 & 13 \\
\hline Fernando VI & 57 & 8 & 14 \\
\hline Carlos III & 224 & 40 & 18 \\
\hline 1789-1799 & 96 & 11 & 11 \\
\hline
\end{tabular}

Mayor magnitud tuvo el acceso a la nobleza de los criollos enriquecidos en América, a quienes se les abrió la puerta del ennoblecimiento con las ventas masivas de títulos llevadas a cabo en la segunda mitad del XVII y la supresión del requisito de no realizar actividades mercantiles, Ilegando ya a suponer el $15 \%$ de las concesiones durante el reinado de Carlos II. Ya en el XVIII, a las ventas de títulos se le sumará el deseo de la Corona por pagar fidelidades a las élites criollas por su participación en las milicias coloniales o en los puestos de gobierno. En esta época, sobre todo en los reinados de Fernando VI y Carlos III, supondrán un $40 \%$ de los nuevos nobles titulados. Aunque la mayoría habían ocupado puestos militares o de gobierno de alguna relevancia ${ }^{15}$, el modo de vida se sus familias era el comercio, la minería y cada vez más la explotación de ingenios azucareros, poco tenían que ver por tanto con los modos de vida de los grandes linajes de la alta nobleza y mucho con las varias decenas de comerciantes asentados en Cádiz que se ennoblecieron por esos mismos años ${ }^{16}$.

14. Los porcentajes que expongo han de entenderse como "porcentajes mínimos", pues las familias enriquecidas con los negocios solían tratar de ocultarlo, incluso en el siglo XVIII.

15. Véase: SANZ TAPIA, A., "Andaluces en cargos políticos hispanoamericanos (16741700)", en Estudios sobre América: siglos XVI-XX, Sevilla, 2005; y id., ¿Corrupción o necesidad? La venta de cargos de gobierno americanos bajo Carlos II (1674-1700), Madrid, 2009.

16. ANES FERNÁNDEZ, L, "Comercio con América y títulos de nobleza: Cádiz en el siglo XVIII", Cuadernos dieciochistas, n² 2, 2001, pp. 109-149. 
TABLA 8. Concesión de títulos nobiliarios a criollos ${ }^{17}$.

\begin{tabular}{|l|c|c|c|}
\hline \multirow{2}{*}{\multicolumn{1}{c|}{ Reinado }} & \multirow{2}{*}{ TOTAL TÍTULOS } & \multicolumn{2}{c|}{ TítULOS A CRIOLLOS } \\
\cline { 3 - 4 } & & $\mathbf{N}^{\mathbf{2}}$ & $\%$ \\
\hline Carlos I & 50 & 3 & 6 \\
\hline Felipe II & 64 & 1 & 2 \\
\hline Felipe III & 114 & 5 & 4 \\
\hline Felipe IV & 268 & 15 & 6 \\
\hline Carlos II & 363 & 53 & 15 \\
\hline Felipe V & 301 & 78 & 26 \\
\hline Fernando VI & 57 & 24 & 42 \\
\hline Carlos III & 224 & 83 & 37 \\
\hline 1789-1799 & 96 & 15 & 16 \\
\hline
\end{tabular}

En cuanto al reconocimiento por la Corona de rangos nobiliarios, los hábitos de las Órdenes Militares suponían el escalafón inmediatamente inferior al de la nobleza titulada. Durante el siglo XVI las concesiones de hábitos, que todavía no eran venales, fueron acaparadas en buena medida por nobles titulados, por segundones de los linajes nobiliarios bajomedievales o por señores de vasallos sin título. La Orden de Calatrava, por ejemplo, que sería luego conocida como la de los burócratas, seguía siendo en el XVI sumamente aristocrática, con un $60 \%$ de los hábitos concedidos a personas vinculadas con la alta nobleza -más otro $13 \%$ de familias con antepasados ya miembros de las Órdenes-, mientras que burócratas, militares y élites locales sólo recibieron un $16 \%$ de las concesiones.

17. La relación de títulos no es coincidente según autores, yo utilizo la de ATIENZA, J. de, Títulos nobiliarios hispano-americanos, Madrid, Aguilar, 1947. Sobre este fenómeno véase: MARURI VILLANUEVA, R., "Poder con poder se paga: títulos nobiliarios beneficiados en Indias (1681-1821)", Revista de Indias, n² 246, 2009, pp. 207-240. 
Tabla 9. Origen de los Caballeros de Calatrava (s. XVI) ${ }^{18}$.

\begin{tabular}{|l|c|}
\hline \multicolumn{1}{|c|}{ Categoría } & \% \\
\hline Nobles titulados & 11 \\
\hline Nobles cortesanos & 20 \\
\hline Segundones Alta Nobleza & 29 \\
\hline Hidalgos caballeros de Órdenes & 13 \\
\hline Total élite nobiliaria & $\mathbf{7 3}$ \\
\hline Élites locales & 3 \\
\hline Burocracia & 10 \\
\hline Militares & 3 \\
\hline Total resto & $\mathbf{1 6}$ \\
\hline Sin clasificar & 11 \\
\hline
\end{tabular}

Pero en el siglo XVII, para desesperación de muchos ${ }^{19}$, las Órdenes se abrieron socialmente. Las grandes beneficiaras, como ocurrió con los títulos nobiliarios, fueron las élites locales, que accedieron a los hábitos mediante compra o por sus servicios en las Cortes u otros apoyos a la Corona durante la recaudación de impuestos o las levas de soldados y aprovechando, como veremos, los lazos clientelares y de parentesco que mantenían con los grandes linajes de funcionarios cortesanos ${ }^{20}$.

18. Los datos proceden de FERNÁNDEZ IZQUIERDO, F., La orden militar de Calatrava en el siglo XVI: infraestructura institucional: sociología y prosopografía de sus caballeros, Madrid, CSIC, 1992, p. 344.

19. Las ordenanzas que regulaban las investigaciones genealógicas que debían superar los beneficiarios de un hábito eran, formalmente, mucho más duras desde mediados del $\mathrm{XVI}$, pero en la práctica resultaron poco efectivas para evitar la concesión de hábitos a comerciantes o hacendados enriquecidos. Según los datos que aporta L. P. Wright, sólo 25 candidatos fueron rechazados en la Orden de Santiago durante el reinado de Felipe III por "falta de nobleza" u "oficio vil", y 184 durante el de Felipe IV, sobre más de 4.000 hábitos concedidos. Cfr. WRIGHT, L. P., "Las Órdenes Militares en la sociedad española de los siglos XVI y XVII", en ELLIOT, J. H., Poder y sociedad en la España de los Austrias, Barcelona, 1882, pp. 15-56.

20. Véase FERNÁNDEZ IZQUIERDO, F., "Los caballeros cruzados en el ejército de la Monarquía Hispánica durante los siglos XVI y XVII: ¿anhelo o realidad?", Revista de Historia Moderna, 22, 2004, pp. 11-60; y JIMÉNEZ MORENO, A., Nobleza, guerra y servicio a la Corona: Los caballeros de hábito en el siglo XVII, Madrid, Tesis Doctoral, 2011. 
TABLA 10. Caballeros de las órdenes militares en el s. XVII ${ }^{21}$.

\begin{tabular}{|l|c|c|c|c|c|c|}
\hline \multirow{2}{*}{ Origen geográfico } & \multicolumn{2}{|c|}{ MILITARES } & \multicolumn{2}{c|}{ BUROCRACIA } & \multicolumn{2}{c|}{$\begin{array}{c}\text { ÉLITES } \\
\text { LOCALES }\end{array}$} \\
\cline { 2 - 7 } & $\mathbf{N}^{\mathbf{0}}$ & $\mathbf{\%}$ & $\mathbf{N}^{\mathbf{0}}$ & $\mathbf{\%}$ & $\mathbf{N}^{\mathbf{0}}$ & $\mathbf{\%}$ \\
\hline Ciudad de Guadalajara & 1 & 3 & 9 & 27 & 23 & 70 \\
\hline Ciudad de Cuenca & 3 & 10 & 5 & 17 & 22 & 73 \\
\hline La Rioja $^{1}$ & 4 & 10 & 9 & 23 & 26 & 67 \\
\hline TOTAL & $\mathbf{8}$ & $\mathbf{8}$ & $\mathbf{2 3}$ & $\mathbf{2 2}$ & $\mathbf{7 1}$ & $\mathbf{7 0}$ \\
\hline
\end{tabular}

1. Exceptuada la ciudad de Logroño.

Éstas élites locales, constituidas usualmente a partir de matrimonios entre linajes hidalgos y hacendados o comerciantes ricos, formaron sólidas oligarquías locales que, en la mayoría de los casos, perdurarían hasta la liquidación del Antiguo Régimen y utilizarían los hábitos, entre otras estrategias, para llevar a cabo un proceso de selección de cuadros que dejaría fuera de la condición nobiliaria a buena parte de las familias hidalgas pobres. En Logroño, por ejemplo, mientras que 16 linajes recibían diversos hábitos de las Órdenes durante el siglo $\mathrm{XVII}$, todos ellos perfectamente integrados en la oligarquía local de regidores perpetuos, el porcentaje de hidalgos se reducía de un 35\% en 1454 a un 9\% en 1587, y seguiría bajando después. En Cuenca, donde 30 de sus vecinos hidalgos recibían hábitos, el porcentaje de hidalgos reconocidos pasó de un 12,8\% a un 7,5\% entre 1598 y $1638^{22}$-en Guadalajara, donde se concedieron 33 hábitos, el porcentaje no descendería hasta el siglo XVIII ${ }^{23}$, pasando de ser el $12,5 \%$ en 1591 al 2,37\% en $1759^{24}$-. Este grupo social será el protagonista de la ruptura

21. Como fuente se han utilizado los expedientes conservados en la Secc. de Órdenes Militares del Archivo Histórico Nacional. Otros estudios locales ofrecen resultados parecidos, como el realizado en Jaén por DELGADO BARRADO, J. M. y LÓPEZ ARANDIA, M. A., "Ciudad y privilegio. Los caballeros de Santiago de Jaén en la Edad Moderna", Boletín. Instituto de Estudios Gienenses, 2010, n 201, pp. 131-160, donde en el siglo XVII sólo 4 de los 28 caballeros de Órdenes tenían servicios militares o burocráticos personales a la Corona, un $14 \%$.

22. Cfr. CARRASCO, R., "Les hidalgos de Cuenca à l'époque moderne", en Hidalgos \& hidalguía dans I'Espagne des XVle-XVIIle siècles, París, 1989, p. 173.

23. Véase: RUBIO FUENTES, M., "Evolución demográfica de Guadalajara durante los siglos XVI y XVII", Wad-al-Hayara: Revista de estudios de Guadalajara, n'. 25, 1998, pp. 91-116; y SALGADO OLMEDA, F., Oligarquía urbana y gobierno de la ciudad de Guadalajara en el siglo XVIII (1718-1788), Guadalajara, 2003.

24. Como es sabido, la reducción del número de hidalgos, en parte por la pérdida de privilegios efectivos del grupo, en parte por la política restrictiva de la Corona, iniciada con las pragmáticas de 1593 y 1623, fue generalizada en casi toda España, de modo que el porcentaje de hidalgos pasó del 13,9\% en 1591, al 7,7\% en 1768 y al 4,6\% en 1787, según CHICARRO, 
de las barreras que protegían a la alta nobleza de origen bajomedieval. Lo podrá conseguir, en primer término, convirtiéndose en oligarquías locales. En Logroño, por ejemplo, las 16 familias que Ilegaron a recibir un hábito de las Órdenes Militares controlarán el Ayuntamiento desde finales del siglo XVI, independientemente de que hubiese regimientos perpetuos o electivos:

Tabla 11. Presencia de las familias hidalgas ricas en el concejo de Logroño ${ }^{25}$.

\begin{tabular}{|l|c|c|}
\hline \multicolumn{1}{|c|}{ Periodo } & $\begin{array}{c}\text { \% REGIMIENTOS } \\
\text { OCUPADOS }\end{array}$ & SISTEMA DE ELECCIÓN \\
\hline $1584-1596$ & 71 & perpetuos \\
\hline $1596-1629$ & 53 & electivos \\
\hline $1629-1651$ & 79 & perpetuos \\
\hline $1654-1657$ & 68 & electivos \\
\hline 1659 & 62 & perpetuos \\
\hline
\end{tabular}

El segundo pilar de su ascenso social fue el servicio a la Corona en la burocracia, fundamentalmente a partir de la Universidad. Las 16 familias logroñesas que citábamos antes colocaron, sólo entre los oidores de los Consejos, a 38 miembros o parientes de sus linajes durante el siglo $\mathrm{XVII}^{26}$. En los lugares que hemos computado a partir de los expedientes conservados en el Archivo Histórico Nacional, comprobamos la estrecha vinculación existente entre estas élites locales y la burocracia -un 50\% de los caballeros o de sus allegados ocupan cargos en la Corte-, a mucha distancia del servicio en el Ejército y a la alta nobleza. En última instancia, lo que se desprende es que burócratas y élites locales son, en realidad, el mismo grupo social, que mantendrá estrechos vínculos clientelares y matrimoniales incluso varias generaciones después de que uno o varios miembros del linaje se hubiesen asentado en la Corte ${ }^{27}$.

M, F. "La evolución de los hidalgos según datos estadísticos", en XXV años de la Escuela de Genealogía, Madrid, 1985, pp. 219-229.

25. Información más extensa en LORENZO CADARSO, P. L., "Luchas políticas y refeudalización en Logroño en los siglos XVI y XVII", Historia Social, 1989, n 5, pp. 3-25.

26. La información procede de BURGOS ESTEBAN, F. M., Los lazos del poder: obligaciones y parentesco en una élite local castellana en los siglos XVI y XVII, Valladolid, Universidad de Valladolid, 1994.

27. Véase IMíZCOZ, J. M. (dir.), Élites, poder y red social. Las élites del País Vasco y Navarra en la Edad Moderna, Bilbao, 1996; MARTíNEZ MILLÁN, J., "Las investigaciones sobre patronazgo y clientelismo en la Administración de la monarquía hispana durante la Edad Moderna", Studia Historica, Historia Moderna, no 15, 1997; SÁNCHEZ LEÓN, P., "Nobleza, estado y clientelas en el feudalismo. En los límites de la Historia Social", en CASTILLO, S. (coord.), La Historia Social en España. Actualidad y perspectivas, Madrid, 1991, pp. 197-215. 
TABLA 12. Vinculaciones de los caballeros de órdenes con la burocracia, el ejército y la alta nobleza (s. XVII).

\begin{tabular}{|l|c|c|c|c|c|c|c|c|}
\hline \multirow{2}{*}{ Territorio } & \multicolumn{2}{|c|}{ BUROCRACIA } & \multicolumn{2}{c|}{ NOBLEZA } & \multicolumn{2}{c|}{ EJÉRCITO } & \multicolumn{2}{|c|}{ NINGUNA } \\
\cline { 2 - 10 } & $\mathbf{N}^{\mathbf{0}}$ & $\mathbf{\%}$ & $\mathbf{N}^{\mathbf{0}}$ & $\mathbf{\%}$ & $\mathbf{N}^{\mathbf{0}}$ & $\mathbf{\%}$ & $\mathbf{N}^{\mathbf{0}}$ & $\mathbf{\%}$ \\
\hline Ciudad de Cuenca & 14 & 48 & 5 & 17 & 1 & 3 & 10 & 34 \\
\hline Ciudad Guadalajara & 19 & 56 & 5 & 15 & 2 & 6 & 8 & 24 \\
\hline La Rioja rural & 20 & 53 & 2 & 5 & 4 & 11 & 12 & 32 \\
\hline TOTAL & $\mathbf{5 2}$ & $\mathbf{5 1}$ & $\mathbf{1 2}$ & $\mathbf{1 2}$ & $\mathbf{7}$ & $\mathbf{7}$ & $\mathbf{3 0}$ & $\mathbf{3 0}$ \\
\hline
\end{tabular}

Paralelamente hubieron de reconstruir sus más que dudosas genealogías, cambiarse los apellidos, destruir documentos, pagar la redacción de estudios genealógicos fantasiosos, comprar testigos, sobornar jueces, comprar títulos y oficios... todo un proceso de invención del pasado que a duras penas se sostenía cuando se enfrentaban a investigaciones serias ${ }^{28}$. En las ciudades de Cuenca y Guadalajara, 33 de los 64 individuos que recibieron un hábito de las Órdenes Militares durante el siglo XVII recibieron recusaciones serias por estar tratando de falsificar su genealogía, y eso que todos los expedientes se tramitaron después de que se eliminara el requisito de no haber sido mercader ni el pretendiente, ni sus padres y abuelos.

TABLA 13. Recusaciones contra los caballeros de órdenes de Cuenca y Guadalajara (s. XVII).

\begin{tabular}{|l|c|c|c|c|}
\hline Ciudad & CONVERSO & BASTARDÍA & $\begin{array}{c}\text { FALTA DE } \\
\text { NOBLEZA }\end{array}$ & NINGUNA \\
\hline Cuenca & 10 & 4 & 6 & 10 \\
\hline Guadalajara & 8 & 0 & 5 & 21 \\
\hline TOTAL & $\mathbf{1 8 ( 2 8 \% )}$ & $\mathbf{4 ( 6 \% )}$ & $\mathbf{1 1 ( 1 7 \% )}$ & $\mathbf{3 1}(\mathbf{4 8} \%)$ \\
\hline
\end{tabular}

28. Sobre estas falsificaciones, véase: CONTRERAS CONTRERAS, J., "Linajes y cambio social: la manipulación de la memoria", Historia Social, 21, 1995, pp. 105-124; SORIA MESA, E., "Genealogía y poder. Invención del pasado y ascenso social en la España moderna", Estudis. Revista de Historia Moderna, 30, 2004, pp. 21-55; FELICES DE LA FUENTE, M. M., "Silencio y ocultaciones en los despachos de los títulos nobiliarios. Análisis crítico de su contenido", Chronica Nova, no 36, 2010, pp. 229-252; y PÉREZ LEÓN, J., "El fraude en la hidalguía: intrusiones en el estado de hijosdalgo durante el siglo XVIII", Estudios Humanísticos. Historia, no 9, 2010, pp. 121-141. 
Los militares fueron otro grupo clave en los procesos de ascenso social durante el Antiguo Régimen, decididamente apoyados por la Corona y, a partir del siglo XVIII, promoviendo no sólo su profesionalización, sino también acudiendo a ellos para cubrir importantes responsabilidades de gobierno, como veremos luego. Como parte de esta política, los servicios en el Ejército fueron recompensados con profusión con títulos nobiliarios ${ }^{29}$ y se intentó reconvertir a las Ordenes Militares en una distinción adicional para los altos oficiales del Ejército y la Marina.

TABLA 14. Los militares en las órdenes militares ${ }^{30}$.

Números absolutos

\begin{tabular}{|l|c|c|c|c|c|c|}
\hline & \multicolumn{7}{|c|}{ PERÍODO } \\
\cline { 2 - 7 } & $\mathbf{1 5 0 0 - 1 5 5 0}$ & $\mathbf{1 5 5 1 - 1 6 0 0}$ & $\mathbf{1 6 0 1 - 1 6 5 0}$ & $\mathbf{1 6 5 1 - 1 7 0 0}$ & $\mathbf{1 7 0 1 - 1 7 5 0}$ & $\mathbf{1 7 5 1 - 1 8 0 0}$ \\
\hline Santiago & $9 / 475$ & $43 / 778$ & $231 / 2858$ & $292 / 2936$ & $356 / 1220$ & $588 / 1110$ \\
\hline Calatrava & $3 / 92$ & $2 / 178$ & $26 / 736$ & $42 / 1256$ & $14 / 438$ & $43 / 269$ \\
\hline Alcántara & $3 / 67$ & $3 / 159$ & $30 / 583$ & $43 / 595$ & $42 / 160$ & $110 / 167$ \\
\hline Montesa & $0 / 2$ & $0 / 105$ & $5 / 151$ & $9 / 152$ & $14 / 56$ & $56 / 89$ \\
\hline
\end{tabular}

Datos porcentuales

\begin{tabular}{|l|c|c|c|c|c|c|}
\hline & \multicolumn{7}{|c|}{ PERíODO } \\
\cline { 2 - 7 } & $\mathbf{1 5 0 0 - 1 5 5 0}$ & $\mathbf{1 5 5 1 - 1 6 0 0}$ & $\mathbf{1 6 0 1 - 1 6 5 0}$ & $\mathbf{1 6 5 1 - 1 7 0 0}$ & $\mathbf{1 7 0 1 - 1 7 5 0}$ & $\mathbf{1 7 5 1 - 1 8 0 0}$ \\
\hline Santiago & 1,89 & 5,53 & 8,08 & 9,95 & 29,18 & 52,97 \\
\hline Calatrava & 3,26 & 1,12 & 3,53 & 3,34 & 3,196 & 15,99 \\
\hline Alcántara & 4,48 & 1,89 & 5,15 & 7,23 & 26,25 & 65,87 \\
\hline Montesa & 0 & 0 & 3,31 & 5,92 & 25 & 62,92 \\
\hline
\end{tabular}

Para quienes no pertenecían a la alta nobleza, ya en el siglo XVIII se crearon también otras distinciones que escaparon casi por completo al control de la aristocracia. La más importante fue la Orden de Carlos III, pensada específicamente para premiar los servicios al Estado en la burocracia y el ejército, que supondrán en torno al $80 \%$ de las concesiones, frente a las tradicionales funciones reservadas a la alta nobleza, como pudieran ser los cargos cortesanos.

29. Véase MORALES MOYA, A., "Milicia y nobleza en el siglo XVIII. (Apuntes para una sociología de las armas y de la nobleza en España)", Cuadernos de Historia Moderna, no 9, 1988, pp. 121-137; y FANTONI Y BENEDÍ, R., "Títulos y grandezas de España concedidos al estamento militar por Carlos II (1665-1700)", Emblemata, 13 (2007), pp. 257-270.

30. Datos procedentes de FERNÁNDEZ IZQUIERDO, F., "Los caballeros 'cruzados' en el ejército de la Monarquía Hispánica durante los siglos XVI y XVII: ¿anhelo o realidad?", Revista de historia moderna: Anales de la Universidad de Alicante, n 22, 2004 (Ejemplar dedicado a: Ejércitos en la Edad Moderna), pp. 11-60. También puede consultarse Nobleza, guerra y servicio a la Corona: Los caballeros de hábito en el siglo XVII, Madrid, Tesis Doctoral, 2011. 
Tabla 15. Caballeros de la Orden de Carlos III (1771-1772) ${ }^{31}$.

\begin{tabular}{|l|c|c|}
\hline \multicolumn{1}{|c|}{ ACTIVIDAD PROFESIONAL } & $\mathbf{N}^{\mathbf{0}}$ & $\mathbf{\%}$ \\
\hline Magistrados & 31 & 18 \\
\hline Oficiales de las Secretarías & 20 & 12 \\
\hline Servicios en la Hacienda & 19 & 11 \\
\hline Diplomáticos & 9 & 5 \\
\hline Total burócratas & $\mathbf{7 9}$ & $\mathbf{4 6}$ \\
\hline Servicios en la Casa Real & 25 & 15 \\
\hline Eclesiásticos & 13 & 8 \\
\hline Militares & 53 & 31 \\
\hline
\end{tabular}

En cuanto a los méritos que alegaban los candidatos que recibían un título nobiliario, lo primero que sorprende es que el $43 \%$ de los solicitantes no habían acreditado ningún servicio relevante a la Corona. Hasta mediados del XVII solían ser segundones de la nobleza que, si acaso, podían aportar cargos honoríficos cortesanos, pero a partir de Carlos II se sumaron masivamente a este perfil hacendados o comerciantes cuyos méritos nada tenían que ver con la burocracia real o el ejército y que accedían al título normalmente por compra, sin poder alegar más merecimientos que algún oficio municipal, normalmente cargos venales patrimonializados.

TABLA 16. Títulos concedidos sin servicios al rey.

\begin{tabular}{|l|c|c|c|c|}
\hline \multicolumn{1}{|c|}{ Reinado } & $\begin{array}{c}\text { CARGOS } \\
\text { CORTESANOS }\end{array}$ & $\begin{array}{c}\text { OFICIOS } \\
\text { LOCALES }\end{array}$ & $\begin{array}{c}\text { SIN } \\
\text { MÉRITOS }\end{array}$ & $\begin{array}{c}\text { \% DEL } \\
\text { TOTAL }\end{array}$ \\
\hline 1500-1515 & 1 & 0 & 3 & 27 \\
\hline Carlos I & 4 & 2 & 15 & 42 \\
\hline Felipe II & 1 & 0 & 19 & 31 \\
\hline Felipe III & 8 & 2 & 45 & 48 \\
\hline Felipe IV & 19 & 15 & 97 & 49 \\
\hline Carlos II & 22 & 64 & 92 & 49 \\
\hline Felipe V & 9 & 51 & 49 & 36 \\
\hline Fernando VI & 0 & 6 & 13 & 33 \\
\hline Carlos III & 5 & 39 & 48 & 41 \\
\hline 1789-1799 & 0 & 32 & 19 & 45 \\
\hline TOTAL & $\mathbf{6 9}$ & $\mathbf{2 1 1}$ & $\mathbf{4 0 0}$ & $\mathbf{4 3}$ \\
\hline
\end{tabular}

31. La información, reelaborada por mi, procede de MORETA I MUNUJOS, J., "Los caballeros de Carlos III. Aproximación social", Hispania, 148 (1981), pp. 409-421. Hay estudios regionales para Aragón, Valencia y Cataluña hechos por MOLAS, P., por ejemplo: "Caballeros valencianos en la orden de Carlos III", Estudis: Revista de Historia Moderna, n 25, 1999, pp. 231-244. En Valencia, por ejemplo, sólo 9 caballeros de esta Orden fueron nobles titulados. 
TABLA 17. Origen social de los nuevos nobles titulados sin servicios al rey.

\begin{tabular}{|l|c|c|c|c|}
\hline \multirow{2}{*}{ Reinado } & \multicolumn{2}{|c|}{ LINAJES DE LA ALTA NOBLEZA } & \multicolumn{2}{c|}{ OTROS } \\
\cline { 2 - 5 } & $\mathbf{N}^{\mathbf{0}}$ & $\mathbf{\%}$ & $\mathbf{N}^{\mathbf{0}}$ & $\mathbf{\%}$ \\
\hline 1500-1515 & 4 & 100 & 0 & 0 \\
\hline Carlos I & 21 & 100 & 0 & 0 \\
\hline Felipe II & 18 & 90 & 2 & 10 \\
\hline Felipe III & 57 & 100 & 0 & 0 \\
\hline Felipe IV & 119 & 91 & 12 & 8 \\
\hline Carlos II & 66 & 37 & 112 & 63 \\
\hline Felipe V & 33 & 30 & 76 & 27 \\
\hline Fernando VI & 4 & 21 & 15 & 79 \\
\hline Carlos III & 13 & 14 & 79 & 86 \\
\hline 1789-1799 & 6 & 12 & 45 & 88 \\
\hline TOTAL & $\mathbf{3 4 1}$ & $\mathbf{5 0}$ & $\mathbf{3 4 1}$ & $\mathbf{5 0}$ \\
\hline
\end{tabular}

Los méritos alegados por quienes sí habían servido al Estado eran en un 34\% méritos militares - desde simples capitanes hasta altos mandos- $y$ en un $37 \%$ relacionados con la alta burocracia civil -miembros de los consejos, embajadores, secretarios, virreyes y capitanes generales borbónicos-. El resto, un 29\%, eran servicios burocráticos en puestos de menor relieve y alejados de la Corte, como las audiencias, los corregimientos o las gobernaciones. El cambio del perfil de los receptores y la pérdida del control de la alta nobleza sobre el proceso se observa con claridad si comparamos a quienes alegan los típicos méritos nobiliarios -embajadores, virreyes, capitanes generales, comendadores de Órdenes y altos mandos del ejército-, que suponen un $67 \%$ en el siglo XVI frente a un $30 \%$ en el XVIII. En el extremo opuesto, los méritos burocráticos y los militares de baja graduación suponían un $26 \%$ en el XVI y pasaron a ser un $69 \%$ en el XVIII.

TABLA 18. Servicios al rey de la nueva nobleza titulada (I) Burocracia (números absolutos y \% de cada reinado).

\begin{tabular}{|c|c|c|c|c|c|c|c|c|c|c|c|c|}
\hline \multirow[t]{2}{*}{ Reinado } & \multicolumn{2}{|c|}{ Eclesiásticos } & \multicolumn{2}{|c|}{$\begin{array}{c}\text { Procs. en } \\
\text { Cortes }\end{array}$} & \multicolumn{2}{|c|}{ Embajadores } & \multicolumn{2}{|c|}{$\begin{array}{c}\text { Corregidores } \\
\text { Intendentes }\end{array}$} & \multicolumn{2}{|c|}{$\begin{array}{l}\text { Caps Gen. } \\
\text { Virreyes }\end{array}$} & \multicolumn{2}{|c|}{ Gobernadores } \\
\hline & $\mathrm{N}^{0}$ & $\%$ & $\mathrm{~N}^{\mathrm{o}}$ & $\%$ & $\mathbf{N}^{\circ}$ & $\%$ & $\mathrm{~N}^{0}$ & $\%$ & $\mathrm{~N}^{0}$ & $\%$ & $\mathbf{N}^{\circ}$ & $\%$ \\
\hline 1500-1515 & 0 & 0 & 0 & 0 & 2 & 13 & 1 & 7 & 7 & 47 & 1 & 7 \\
\hline Carlos I & 0 & 0 & 0 & 0 & 1 & 3 & 1 & 3 & 16 & 50 & 3 & 9 \\
\hline Felipe II & 0 & 0 & 0 & 0 & 4 & 9 & 1 & 2 & 13 & 30 & 6 & 14 \\
\hline Siglo XVI & 0 & 0 & 0 & 0 & 7 & 8 & 3 & 3 & 36 & 40 & 10 & 11 \\
\hline
\end{tabular}




\begin{tabular}{|l|c|c|c|c|c|c|c|c|c|c|c|c|}
\hline \multirow{2}{*}{ Reinado } & \multicolumn{2}{|c|}{ Eclesiásticos } & \multicolumn{2}{c|}{$\begin{array}{c}\text { Procs. en } \\
\text { Cortes }\end{array}$} & \multicolumn{2}{|c|}{ Embajadores } & \multicolumn{2}{c|}{$\begin{array}{c}\text { Corregidores } \\
\text { Intendentes }\end{array}$} & \multicolumn{2}{c|}{$\begin{array}{c}\text { Caps Gen. } \\
\text { Virreyes }\end{array}$} & \multicolumn{2}{|c|}{ Gobernadores } \\
\cline { 2 - 16 } & $\mathbf{N}^{\mathbf{0}}$ & $\mathbf{\%}$ & $\mathbf{N}^{\mathbf{0}}$ & $\mathbf{\%}$ & $\mathbf{N}^{\mathbf{0}}$ & $\mathbf{\%}$ & $\mathbf{N}^{\mathbf{0}}$ & $\mathbf{\%}$ & $\mathbf{N}^{\mathbf{0}}$ & $\mathbf{\%}$ & $\mathbf{N}^{\mathbf{0}}$ & $\mathbf{\%}$ \\
\hline Felipe III & 1 & 2 & 0 & 0 & 7 & 11 & 2 & 3 & 15 & 24 & 2 & 3 \\
\hline Felipe IV & 4 & 2 & 3 & 2 & 10 & 6 & 13 & 7 & 30 & 17 & 27 & 15 \\
\hline Carlos II & 8 & 3 & 4 & 2 & 7 & 3 & 23 & 10 & 21 & 9 & 24 & 10 \\
\hline Siglo XVII & $\mathbf{1 3}$ & $\mathbf{3}$ & $\mathbf{7}$ & $\mathbf{1}$ & $\mathbf{2 4}$ & $\mathbf{5}$ & $\mathbf{3 8}$ & $\mathbf{8}$ & $\mathbf{6 6}$ & $\mathbf{1 4}$ & $\mathbf{5 3}$ & $\mathbf{1 1}$ \\
\hline Felipe V & 3 & 1 & 7 & 3 & 9 & 3 & 10 & 4 & 19 & 7 & 18 & 7 \\
\hline Fernando VI & 1 & 2 & 0 & 0 & 0 & 0 & 4 & 8 & 3 & 6 & 7 & 14 \\
\hline Carlos III & 1 & 1 & 0 & 0 & 4 & 3 & 6 & 4 & 10 & 7 & 9 & 6 \\
\hline 1789-1799 & 1 & 1 & 2 & 3 & 0 & 0 & 3 & 4 & 6 & 8 & 4 & 5 \\
\hline Siglo XVIII & $\mathbf{6}$ & $\mathbf{1}$ & $\mathbf{9}$ & $\mathbf{2}$ & $\mathbf{1 3}$ & $\mathbf{2}$ & $\mathbf{2 3}$ & $\mathbf{4}$ & $\mathbf{3 8}$ & $\mathbf{7}$ & $\mathbf{3 8}$ & $\mathbf{7}$ \\
\hline TOTAL & $\mathbf{1 9}$ & $\mathbf{2}$ & $\mathbf{1 6}$ & $\mathbf{1}$ & $\mathbf{4 4}$ & $\mathbf{4}$ & $\mathbf{5 5}$ & $\mathbf{5}$ & $\mathbf{1 4 0}$ & $\mathbf{1 3}$ & $\mathbf{1 0 1}$ & $\mathbf{9}$ \\
\hline
\end{tabular}

TABLA 19. Servicios al rey de la nueva nobleza titulada (II) Burocracia (números absolutos y \% de cada reinado).

\begin{tabular}{|l|c|c|c|c|c|c|c|c|c|c|}
\hline \multirow{2}{*}{ Reinado } & \multicolumn{2}{|c|}{ Secretarios } & \multicolumn{2}{c|}{$\begin{array}{c}\text { Oidores } \\
\text { Consejos }\end{array}$} & \multicolumn{2}{c|}{$\begin{array}{c}\text { Oidores } \\
\text { Audiencias }\end{array}$} & \multicolumn{2}{c|}{$\begin{array}{c}\text { Comendadores } \\
\text { Órdenes }\end{array}$} & \multicolumn{2}{c|}{$\begin{array}{c}\text { Otros } \\
\text { cargos }\end{array}$} \\
\cline { 2 - 12 } & $\mathbf{N}^{\mathbf{0}}$ & $\mathbf{\%}$ & $\mathbf{N}^{\mathbf{0}}$ & $\mathbf{\%}$ & $\mathbf{N}^{\mathbf{0}}$ & $\mathbf{\%}$ & $\mathbf{N}^{\mathbf{0}}$ & $\mathbf{\%}$ & $\mathbf{N}^{\mathbf{0}}$ & $\mathbf{\%}$ \\
\hline 1500-1515 & 0 & 0 & 0 & 0 & 0 & 0 & 0 & 0 & 0 & 0 \\
\hline Carlos I & 1 & 3 & 2 & 6 & 0 & 0 & 3 & 9 & 1 & 3 \\
\hline Felipe II & 0 & 0 & 4 & 12 & 0 & 0 & 3 & 7 & 1 & 2 \\
\hline Siglo XVI & $\mathbf{1}$ & $\mathbf{1}$ & $\mathbf{6}$ & $\mathbf{7}$ & $\mathbf{0}$ & $\mathbf{0}$ & $\mathbf{6}$ & $\mathbf{7}$ & $\mathbf{2}$ & $\mathbf{2}$ \\
\hline Felipe III & 0 & 0 & 7 & 11 & 2 & 3 & 13 & 21 & 1 & 2 \\
\hline Felipe IV & 2 & 1 & 22 & 12 & 2 & 1 & 8 & 5 & 3 & 2 \\
\hline Carlos II & 10 & 4 & 43 & 18 & 15 & 6 & 3 & 1 & 6 & 3 \\
\hline Siglo XVII & $\mathbf{1 2}$ & $\mathbf{3}$ & $\mathbf{7 2}$ & $\mathbf{1 5}$ & $\mathbf{1 9}$ & $\mathbf{4}$ & $\mathbf{2 4}$ & $\mathbf{5}$ & $\mathbf{1 0}$ & $\mathbf{2}$ \\
\hline Felipe V & 11 & 4 & 63 & 23 & 7 & 3 & 3 & 1 & 17 & 6 \\
\hline Fernando VI & 1 & 2 & 3 & 6 & 6 & 12 & 0 & 0 & 1 & 2 \\
\hline Carlos III & 9 & 6 & 29 & 20 & 12 & 8 & 1 & 1 & 7 & 5 \\
\hline 1789-1799 & 5 & 7 & 14 & 19 & 3 & 4 & 1 & 1 & 6 & 8 \\
\hline Siglo XVIII & $\mathbf{2 6}$ & $\mathbf{5}$ & $\mathbf{1 0 9}$ & $\mathbf{2 0}$ & $\mathbf{2 8}$ & $\mathbf{5}$ & $\mathbf{5}$ & $\mathbf{1}$ & $\mathbf{3 1}$ & $\mathbf{6}$ \\
\hline TOTAL & $\mathbf{3 9}$ & $\mathbf{4}$ & $\mathbf{1 7 7}$ & $\mathbf{1 6}$ & $\mathbf{4 7}$ & $\mathbf{4}$ & $\mathbf{3 5}$ & $\mathbf{3}$ & $\mathbf{4 3}$ & $\mathbf{4}$ \\
\hline
\end{tabular}

1. Se incluyen veedores, proveedores, tesoreros, administradores y superintendentes. 
TABLA 20. Servicios al rey de la nueva nobleza titulada (III) Militares (números absolutos y \% de cada reinado).

\begin{tabular}{|l|c|c|c|c|c|c|c|c|c|c|}
\hline \multirow{2}{*}{ Reinado } & \multicolumn{2}{|c|}{ Capitanes } & \multicolumn{2}{c|}{$\begin{array}{c}\text { Sargentos } \\
\text { Mayores }\end{array}$} & \multicolumn{2}{c|}{ Coroneles } & \multicolumn{2}{c|}{$\begin{array}{c}\text { Maestres } \\
\text { de Campo }\end{array}$} & \multicolumn{2}{c|}{$\begin{array}{c}\text { Altos } \\
\text { mandos }^{1}\end{array}$} \\
\cline { 2 - 13 } & $\mathbf{N}^{\mathbf{0}}$ & $\mathbf{\%}$ & $\mathbf{N}^{\mathbf{0}}$ & $\mathbf{\%}$ & $\mathbf{N}^{\mathbf{0}}$ & $\mathbf{\%}$ & $\mathbf{N}^{\mathbf{0}}$ & $\mathbf{\%}$ & $\mathbf{N}^{\mathbf{0}}$ & $\mathbf{\%}$ \\
\hline $1500-1515$ & 0 & 0 & 0 & 0 & 0 & 0 & 0 & 0 & 4 & 27 \\
\hline Carlos I & 1 & 3 & 0 & 0 & 0 & 0 & 0 & 0 & 3 & 9 \\
\hline Felipe II & 1 & 2 & 0 & 0 & 0 & 0 & 2 & 5 & 8 & 19 \\
\hline Siglo XVI & $\mathbf{2}$ & $\mathbf{2}$ & $\mathbf{0}$ & $\mathbf{0}$ & $\mathbf{0}$ & $\mathbf{0}$ & $\mathbf{2}$ & $\mathbf{2}$ & $\mathbf{1 5}$ & $\mathbf{1 7}$ \\
\hline Felipe III & 3 & 5 & 0 & 0 & 1 & 2 & 6 & 10 & 3 & 5 \\
\hline Felipe IV & 10 & 6 & 0 & 0 & 0 & 0 & 20 & 11 & 22 & 12 \\
\hline Carlos II & 17 & 7 & 1 & 0,4 & 2 & 1 & 36 & 15 & 15 & 6 \\
\hline Siglo XVII & $\mathbf{3 0}$ & $\mathbf{6}$ & $\mathbf{1}$ & $\mathbf{0 , 2}$ & $\mathbf{3}$ & $\mathbf{0 , 6}$ & $\mathbf{6 2}$ & $\mathbf{1 3}$ & $\mathbf{4 0}$ & $\mathbf{8}$ \\
\hline Felipe V & 15 & 6 & 5 & 2 & 28 & 10 & 19 & 7 & 37 & 14 \\
\hline Fernando VI & 3 & 6 & 0 & 0 & 9 & 18 & 4 & 8 & 9 & 18 \\
\hline Carlos III & 12 & 8 & 1 & 1 & 22 & 15 & 1 & 1 & 28 & 20 \\
\hline 1789-1799 & 7 & 9 & 0 & 0 & 6 & 8 & 0 & 0 & 16 & 22 \\
\hline Siglo XVIII & $\mathbf{3 7}$ & $\mathbf{7}$ & $\mathbf{6}$ & $\mathbf{1}$ & $\mathbf{6 5}$ & $\mathbf{1 2}$ & $\mathbf{2 4}$ & $\mathbf{4}$ & $\mathbf{9 0}$ & $\mathbf{1 6}$ \\
\hline TOTAL & $\mathbf{6 9}$ & $\mathbf{6}$ & $\mathbf{7}$ & $\mathbf{1}$ & $\mathbf{6 8}$ & $\mathbf{6}$ & $\mathbf{8 8}$ & $\mathbf{8}$ & $\mathbf{1 4 5}$ & $\mathbf{1 3}$ \\
\hline
\end{tabular}

1. Se incluyen capitanes generales, tenientes generales, almirantes, brigadieres y mariscales.

Por lo que respecta a los méritos específicos de los miembros de los linajes de la alta nobleza que accedieron a títulos, podemos comprobar que la gran mutación se produce en la segunda mitad del siglo XVIII, cuando se detecta que la fuerte caída del número de títulos concedidos a este colectivo social fue especialmente intensa entre quienes podían alegar servicios políticos a la Corona: los 90 títulos concedidos a personas con este perfil en el siglo XVII pasaron a ser 20 en el siglo XVIII -5 en toda su segunda mitad-, una caída del $78 \%$, resultado de la pérdida de poder político de este colectivo en dicha centuria, como cuantificaremos más adelante. También es significativo comprobar cómo los 43 títulos que se concedieron en el siglo XVII por ejercer cargos cortesanos pasaron a ser 3 en el siglo XVIII, una caída del $93 \%$, lo que nos habla del nuevo ambiente cortesano que se respiraba bajo los Borbones. 
Tabla 21. Méritos de los nuevos nobles que pertenecían a linajes de la alta nobleza.

\begin{tabular}{|l|c|c|c|c|c|c|c|c|}
\hline \multirow{2}{*}{ Reinado } & \multicolumn{2}{c|}{$\begin{array}{c}\text { SIN } \\
\text { MÉRITOS }\end{array}$} & \multicolumn{2}{c|}{$\begin{array}{c}\text { MÉRITOS } \\
\text { CORTESANOS }\end{array}$} & \multicolumn{2}{c|}{$\begin{array}{c}\text { MÉRITOS } \\
\text { MILITARES }\end{array}$} & \multicolumn{2}{c|}{$\begin{array}{c}\text { MÉRITOS } \\
\text { POLÍTICOS }\end{array}$} \\
\cline { 2 - 9 } & $\mathbf{N}^{\mathbf{0}}$ & $\mathbf{\%}$ & $\mathbf{N}^{\mathbf{0}}$ & $\mathbf{\%}$ & $\mathbf{N}^{\mathbf{0}}$ & $\mathbf{\%}$ & $\mathbf{N}^{\mathbf{0}}$ & $\mathbf{\%}$ \\
\hline 1500-1515 & 4 & 27 & 0 & 0 & 4 & 27 & 7 & 46 \\
\hline Carlos I & 18 & 55 & 0 & 0 & 4 & 8 & 11 & 37 \\
\hline Felipe II & 22 & 52 & 1 & 2 & 3 & 6 & 16 & 40 \\
\hline Felipe III & 50 & 56 & 8 & 9 & 6 & 7 & 25 & 28 \\
\hline Felipe IV & 91 & 52 & 19 & 11 & 19 & 11 & 46 & 26 \\
\hline Carlos II & 50 & 53 & 16 & 17 & 9 & 10 & 19 & 20 \\
\hline Felipe V & 32 & 47 & 2 & 3 & 19 & 28 & 15 & 22 \\
\hline Fernando VI & 5 & 71 & 0 & 0 & 2 & 29 & 0 & 0 \\
\hline Carlos III & 17 & 68 & 1 & 4 & 3 & 12 & 4 & 16 \\
\hline 1789-1799 & 10 & 67 & 0 & 0 & 4 & 27 & 1 & 7 \\
\hline TOTAL & $\mathbf{2 9 9}$ & $\mathbf{5 3}$ & $\mathbf{4 7}$ & $\mathbf{8}$ & $\mathbf{7 3}$ & $\mathbf{1 3}$ & $\mathbf{1 4 4}$ & $\mathbf{2 6}$ \\
\hline
\end{tabular}

La alta nobleza fue, como veíamos, un colectivo social en franca expansión cuantitativa durante toda la Edad Moderna -en total, el número de títulos en circulación se multiplica por 12 entre 1500 y 1800 y el de nobles titulados casi por 10, de 140 a 1.300, aproximadamente-, fenómeno de sobra conocido, pero lo realmente trascendente es conocer en qué medida su reforzamiento numérico implicó un aumento equivalente en las parcelas de poder que controlaban los nobles titulados.

Comencemos por la Iglesia, o más específicamente por la élite del clero: obispos, arzobispos y cardenales, cargos apetecidos desde siempre por los grandes linajes nobiliarios para colocar a sus segundones. Lo cierto es que cuando observamos la presencia de aristócratas en estos cargos, comprobamos que la pérdida de poder del grupo comenzó antes que en ningún otro ámbito institucional: en los arzobispados la inflexión es prácticamente continua desde Felipe II y especialmente rotunda durante el reinado de Felipe IV, cuando la presencia de la alta nobleza cae hasta el $35 \%$ de los arzobispos designados, y llegará a ser el 0\% con Carlos III32.

32. Desgraciadamente, la fuente utilizada -diversos episcopologios de cada Obispadono permite reconstruir con precisión el origen social de los nuevos Obispos, únicamente $-y$ no siempre- si descendían de familias de la alta nobleza. Se ha consultado también: ALDEA VAQUERO, Q.; MARIN MARTÍNEZ, T. y VIVES GATELL, J., Diccionario de Historia Eclesiástica de España, Madrid, CSIC Instituto Enrique Flórez, 1972-87, 5 Vols. Véase, para el siglo XVIII, BARRIO GOZALO, M., "Sociología del alto clero en la España del siglo ilustrado", Manuscrits, 20, 2002, pp. 29-59. 
TABLA 22. Presencia de la alta nobleza en los arzobispados (por reinados, incluyendo el Obispado de Barcelona).

\begin{tabular}{|l|c|c|c|}
\hline \multicolumn{1}{|c|}{ Reinado } & $\begin{array}{c}\mathbf{N}^{\mathbf{0}} \text { DE } \\
\text { ARZOBISPOS }\end{array}$ & $\begin{array}{c}\text { LINAJES ALTA } \\
\text { NOBLEZA }\end{array}$ & $\begin{array}{c}\% \\
\text { NOBLES }\end{array}$ \\
\hline 1500-1515 & 11 & 8 & 73 \\
\hline Carlos I (1516-1555) & 35 & 23 & 66 \\
\hline Felipe II (1556-1598) & 46 & 21 & 46 \\
\hline Felipe III (1599-1620) & 25 & 15 & 60 \\
\hline Felipe IV (1621-1665) & 57 & 20 & 35 \\
\hline Carlos II (1666-1700) & 49 & 12 & 24 \\
\hline Felipe V (1700-1745) & 43 & 5 & 12 \\
\hline Fernando VI (1746-1759) & 16 & 2 & 12 \\
\hline Carlos III (1760-1788) & 21 & 0 & 0 \\
\hline Carlos IV (1789-1799) & 11 & 4 & 36 \\
\hline TOTAL & $\mathbf{3 1 4}$ & $\mathbf{1 1 0}$ & $\mathbf{3 5}$ \\
\hline
\end{tabular}

Los obispados presentan una tendencia similar -más acusada si cabe-, de modo que parece obvio que los acuerdos del Concilio de Trento y sus exigencias en orden a designar obispos realmente cualificados para desempeñar sus cargos fueron en gran medida efectivos; de hecho, la presencia de catedráticos y doctores universitarios es abrumadora desde finales del XVI, e incluso muchos de los obispos vinculados con los linajes de la alta nobleza se veían obligados, antes de recibir el cargo, a pasar por las aulas universitarias.

TABLA 23. Presencia de la alta nobleza en los obispados (excepto Barcelona).

\begin{tabular}{|c|c|c|c|}
\hline Reinado & NN OBISPOS & $\begin{array}{l}\text { LINAJES ALTA } \\
\text { NOBLEZA }\end{array}$ & $\%$ NOBLES \\
\hline 1500-1516 & 64 & 29 & 45 \\
\hline Carlos I & 158 & 83 & 52 \\
\hline Felipe II & 221 & 86 & 39 \\
\hline Felipe III & 108 & 36 & 33 \\
\hline Felipe IV & 302 & 89 & 29 \\
\hline Carlos II & 156 & 29 & 18 \\
\hline Felipe V & 182 & 33 & 18 \\
\hline Fernando VI & 54 & 9 & 17 \\
\hline Carlos III & 107 & 8 & 7 \\
\hline 1789-1799 & 42 & 5 & 12 \\
\hline TOTAL & 1.394 & 407 & 29 \\
\hline
\end{tabular}


Los capelos cardenalicios, como cabía esperar, fueron menos abiertos socialmente, y además en ellos el fenómeno de la caída de la presencia nobiliaria es menos acusado y más tardío cronológicamente, pues no se hace patente hasta el siglo XVIII.

TABLA 24. Presencia de la alta nobleza entre los cardenales españoles ${ }^{33}$.

\begin{tabular}{|l|c|c|c|}
\hline \multicolumn{1}{|c|}{ Reinado } & $\begin{array}{c}\mathbf{N}^{\mathbf{0}} \\
\text { CARDENALES }\end{array}$ & $\begin{array}{c}\text { LINAJES } \\
\text { ALTA NOBLEZA }\end{array}$ & $\begin{array}{c}\text { \% } \\
\text { NOBLES }\end{array}$ \\
\hline $1500-1515$ & 13 & 6 & 46 \\
\hline Carlos I & 18 & 13 & 72 \\
\hline Felipe II & 14 & 8 & 57 \\
\hline Siglo XVI & $\mathbf{4 5}$ & $\mathbf{2 7}$ & $\mathbf{6 0}$ \\
\hline Felipe III & 6 & 4 & 66 \\
\hline Felipe IV & 10 & 8 & 80 \\
\hline Carlos II & 6 & 3 & 50 \\
\hline Siglo XVII & $\mathbf{2 2}$ & $\mathbf{1 5}$ & $\mathbf{6 8}$ \\
\hline Felipe V & 9 & 3 & 33 \\
\hline Fernando VI & 3 & 3 & 100 \\
\hline Carlos III & 3 & 2 & 66 \\
\hline Carlos IV & 2 & 0 & 0 \\
\hline Siglo XVIII & $\mathbf{1 7}$ & $\mathbf{8}$ & $\mathbf{4 7}$ \\
\hline TOTAL & $\mathbf{8 4}$ & $\mathbf{5 0}$ & $\mathbf{5 9}$ \\
\hline
\end{tabular}

La Inquisición, creada y controlada en todo momento por el Estado, fue otro centro de poder importante, al que la alta nobleza accedió con relativo retraso -el primer Inquisidor General vinculado con los linajes bajomedievales fue Alfonso Manrique de Lara en 1523-, pero a partir de Felipe II serán predominantes, especialmente en la segunda mitad del XVII, cuando llegarán a suponer el $80 \%$ de las designaciones. Ya en el XVIII la presencia de inquisidores con este origen social desparece a partir de Fernando VI.

33. El listado y su identificación inicial en BERGIER, N. S., Suplemento al Diccionario de Teología, Madrid, José Lorente, 1857, pp. 134 y ss. 
TABLA 25. Presencia de la alta nobleza entre los inquisidores generales.

\begin{tabular}{|l|c|c|c|c|}
\hline \multirow{2}{*}{\multicolumn{1}{c|}{ Reinado }} & \multicolumn{2}{|c|}{ LINAJES ALTA NOBLEZA } & \multicolumn{2}{c|}{ OTROS } \\
\cline { 2 - 5 } & $\mathbf{N}^{\mathbf{0}}$ & $\mathbf{\%}$ & $\mathbf{N}^{\mathbf{0}}$ & $\mathbf{\%}$ \\
\hline 1500-1515 & 0 & 0 & 4 & 100 \\
\hline Carlos I & 1 & 20 & 4 & 80 \\
\hline Felipe II & 4 & 67 & 2 & 33 \\
\hline Felipe III & 3 & 60 & 2 & 40 \\
\hline Felipe IV & 3 & 60 & 2 & 40 \\
\hline Carlos II & 4 & 80 & 1 & 20 \\
\hline Felipe V & 2 & 22 & 7 & 78 \\
\hline Fernando VI & 0 & 0 & 2 & 100 \\
\hline Carlos III & 0 & 0 & 2 & 100 \\
\hline Carlos IV & 0 & 0 & 3 & 100 \\
\hline TOTAL & $\mathbf{1 7}$ & $\mathbf{3 7}$ & $\mathbf{2 9}$ & $\mathbf{6 3}$ \\
\hline
\end{tabular}

El Ejército, ya lo decíamos antes, fue otro centro de poder importante y una conocida vía para el ascenso social y el ennoblecimiento. Desgraciadamente, es también una parcela de la Administración poco conocida en términos prosopográficos. La cuestión clave en este asunto es conocer su permeabilidad social, esto es, en qué medida los individuos que no estaban vinculados familiarmente con la alta nobleza llegaban a ocupar los altos mandos, los únicos que realmente abrían las puertas para un ascenso social. A lo largo de los siglos XVI y XVII se observa un aumento paulatino de la presencia de nobles titulados entre los altos mandos del ejército europeo, los cargos más prestigiosos de todos, suponiendo un 33\% durante el reinado de Carlos I y alcanzando sus máximos durante el de Felipe IV, con un $62 \%$

TABLA 26. Origen social de algunos altos mandos del ejército Europeo de los Austrias ${ }^{34}$.

\begin{tabular}{|l|c|c|c|c|}
\hline \multirow{2}{*}{\multicolumn{1}{c|}{ Reinado }} & \multicolumn{2}{c|}{ MILITARES } & \multicolumn{2}{c|}{ NOBLES TITULADOS } \\
\cline { 2 - 5 } & $\mathbf{N}^{\mathbf{0}}$ & $\mathbf{\%}$ & $\mathbf{N}^{\mathbf{0}}$ & $\mathbf{\%}$ \\
\hline Carlos I & 12 & 66 & 6 & 33 \\
\hline Felipe II & 31 & 58 & 22 & 41 \\
\hline Felipe III & 9 & 50 & 9 & 50 \\
\hline Felipe IV & 37 & 38 & 59 & 62 \\
\hline Carlos II & 36 & 54 & 30 & 46 \\
\hline TOTAL & $\mathbf{1 2 5}$ & $\mathbf{5 0}$ & $\mathbf{1 2 6}$ & $\mathbf{5 0}$ \\
\hline
\end{tabular}

34. Se han contabilizado la Capitanía General de Artillería de Flandes, la Capitanía General de Caballería de Flandes, la Capitanía General de la Caballería de Milán, la Capitanía General de la Artillería de Milán, los Maestres Generales de Campo Portugal y de Flandes, la Tenencia General de la Caballería de Flandes y la Capitanía General de las Galeras de España. 
Si descendemos un escalón y nos fijamos en los maestres de campo de los tercios, la presencia nobiliaria desciende notablemente, aunque presenta la misma tendencia de aumento en el siglo XVII frente al XVI.

TABLA 27. Presencia de la alta nobleza entre los maestres de campo de los ejércitos de Flandes e Italia.

\begin{tabular}{|l|c|c|c|}
\hline \multicolumn{1}{|c|}{ Reinado } & $\mathbf{N}^{\mathbf{0}}$ MAESTRES & $\begin{array}{c}\text { NOBLES } \\
\text { TITULADOS }\end{array}$ & \% NOBLES \\
\hline Carlos I & 26 & 2 & 7 \\
\hline Felipe II & 67 & 12 & 17 \\
\hline Felipe III & 62 & 21 & 33 \\
\hline Felipe IV & 136 & 43 & 31 \\
\hline Carlos II & 101 & 36 & 35 \\
\hline TOTAL & $\mathbf{3 9 2}$ & $\mathbf{1 1 4}$ & $\mathbf{2 9}$ \\
\hline
\end{tabular}

De algunos tercios podemos reconstruir la cadena de mando completa, lo que los hace más apropiados para su análisis. Observamos en ellos como la presencia real de la alta nobleza en el Ejército de los Austrias fue mucho mayor que la que se desprende del cuadro anterior: efectivamente, si contabilizamos como miembros del grupo también a los hijos y nietos de nobles titulados, el porcentaje de puestos que ocupa este colectivo se multiplica por 2, aproximadamente, monopolizando dos terceras partes de los cargos disponibles.

TABLA 28. Presencia de los linajes de la alta nobleza entre los maestres de campo de la cadena de mando de varios tercios (nobles titulados y segundones) $)^{35}$.

\begin{tabular}{|l|l|l|c|c|}
\hline \multirow{2}{*}{ Periodo } & \multicolumn{2}{|c|}{ PERTENECIENTES } & \multicolumn{2}{c|}{ NO PERTENECIENTES } \\
\cline { 2 - 5 } & $\mathbf{N}^{\mathbf{0}}$ & $\mathbf{\%}$ & $\mathbf{N}^{\mathbf{0}}$ & $\mathbf{\%}$ \\
\hline $1551-1600$ & 16 & 57 & 12 & 43 \\
\hline $1601-1650$ & 43 & 67 & 21 & 33 \\
\hline $1651-1700$ & 27 & 64 & 15 & 36 \\
\hline TOTAL & $\mathbf{8 6}$ & $\mathbf{6 5}$ & $\mathbf{4 8}$ & $\mathbf{3 5}$ \\
\hline
\end{tabular}

35. Se han computado sólo los tercios de infantería española de los que disponía de información amplia sobre su cadena de mando, concretamente los siguientes: $1^{\circ}$ de Saboya, $3^{\circ}$ de Lombardía, Nápoles, Velasco, Bobadilla y $2^{\circ}$ de Sicilia. Se han considerado como vinculados a los linajes de la alta nobleza a los hijos y nietos de nobles titulados. 
El Ejército del siglo XVIII pareció resultar, en términos generales, más atractivo para los nobles -incluidos hidalgos- que en el pasado, al menos así se desprende del pionero trabajo de Andújar Castillo sobre los orígenes sociales de los militares, donde se demuestra un crecimiento paulatino de la presencia de la nobleza entre los oficiales, fenómeno indisoluble del requisito de nobleza que se exigía para ingresar en las academias militares. Según Andújar, el porcentaje de nobles entre los oficiales fue algo superior al 50\% entre 1650 y 1725, pasando a ser más del $70 \%$ a partir de esta última fecha ${ }^{36}$.

Entre los altos mandos del Ejército, según el mismo autor, se mantuvo un porcentaje de nobles titulados que rondó el 30\% -parecido al del siglo XVII entre los maestres de campo-, oscilando entre el $90 \%$ de los capitanes generales y el $18 \%$ de los brigadieres.

TABLA 29. Nobles titulados entre los altos mandos del ejército borbónico.

\begin{tabular}{|c|c|}
\hline FECHA & \% \\
\hline 1711 & 39 \\
\hline 1739 & 32 \\
\hline 1749 & 30 \\
\hline 1759 & 31 \\
\hline 1769 & 33 \\
\hline 1779 & 33 \\
\hline 1789 & 29 \\
\hline 1799 & 20 \\
\hline
\end{tabular}

Un caso peculiar fue la Real Armada, donde se creó un programa de formación especialmente riguroso para sus mandos, lo que tuvo consecuencias importantes en su composición social ${ }^{37}$. La Armada se convirtió, por primera vez, en una institución atractiva para las élites locales y para los propios militares, que no dudarán en introducir a sus hijos en la carrera profesional: Sobre una muestra de 148 designaciones de altos mandos de la Armada que he conseguido documentar -almirantes, brigadieres, capitanes generales, tenientes generales y jefes de escuadra-, entre los dos grupos citados sumarán un $75 \%$ de los altos mandos.

36. Véanse dos trabajos de ANDÚJAR CASTILLO, F., "El ejército borbónico en el último tercio del siglo XVIII: permeabilidad social en una institución nobiliaria", Chronica nova: Revista de historia moderna de la Universidad de Granada, n 40, 2014, pp.131-154; y "La educación de los militares en la España del siglo XVIII", Chronica nova: Revista de historia moderna de la Universidad de Granada, no 19, 1991, pp. 31-56.

37. SÁNCHEZ BAENA, J.J., "Aspirantes a oficiales de la Real Armada en la Academia ilustrada del Mediterráneo: esplendor y crisis (1776-1824)", en GARCÍA HURTADO, M.R. (ed.), La Armada española en el siglo XVIII. Ciencia, hombres y barcos, Madrid, Editorial Sílex, 2012, pp. 329-362. 
TABLA 30. Origen social de los altos mandos de la marina borbónica ${ }^{38}$.

\begin{tabular}{|l|c|c|c|c|c|c|c|c|}
\hline \multirow{2}{*}{ Reinado } & \multicolumn{2}{|c|}{ BUROCRACIA } & \multicolumn{2}{c|}{ MILITARES } & \multicolumn{2}{c|}{$\begin{array}{c}\text { ALTA } \\
\text { NOBLEZA }\end{array}$} & \multicolumn{2}{c|}{$\begin{array}{c}\text { ÉLITES } \\
\text { LOCALES }\end{array}$} \\
\cline { 2 - 9 } & $\mathbf{N}^{\mathbf{0}}$ & $\mathbf{\%}$ & $\mathbf{N}^{\mathbf{0}}$ & $\mathbf{\%}$ & $\mathbf{N}^{\mathbf{0}}$ & $\mathbf{\%}$ & $\mathbf{N}^{\mathbf{0}}$ & $\mathbf{\%}$ \\
\hline Felipe V & 0 & 0 & 3 & 14 & 6 & 29 & 13 & 62 \\
\hline Fernando VI & 0 & 0 & 4 & 333 & 4 & 33 & 4 & 33 \\
\hline Carlos III & 1 & 2 & 10 & 22 & 11 & 24 & 23 & 51 \\
\hline Carlos IV & 5 & 7 & 11 & 16 & 12 & 17 & 41 & 59 \\
\hline TOTAL & $\mathbf{6}$ & $\mathbf{4}$ & $\mathbf{2 8}$ & $\mathbf{2 0}$ & $\mathbf{3 3}$ & $\mathbf{2 2}$ & $\mathbf{8 1}$ & $\mathbf{5 5}$ \\
\hline
\end{tabular}

La alta Administración civil -audiencias, chancillerías y consejos- constituía uno de los principales centros de poder durante los siglos XVI y XVII y el núcleo del creciente poder de los burócratas en la Corte $^{39}$. A la hora de establecer criterios para designar presidentes de Chancillerías y Audiencias, tuvo una importancia capital la mera costumbre. Es lo que ocurrió, por ejemplo, con la Chancillería de Valladolid, tradicionalmente ocupada por un clérigo -costumbre que se extendió temporalmente a Granada- , o con el conjunto de las audiencias, tradicionalmente ocupadas por los capitanes generales, que al carecer de conocimientos jurídicos, no eran sino meros presidentes testimoniales, hasta que en el siglo XVIII se extendió la figura de los regentes, pero ya reservados a oidores letrados.

La alta nobleza tuvo una presencia testimonial en la presidencia de las chancillerías (un $7 \%$ en Valladolid y un $2 \%$ en Granada) y parecida en las regencias de las audiencias borbónicas (un 8\%) ) $^{40}$ la pugna se concentró entre la tradicional costumbre de designar clérigos y la novedad de designar oidores letrados. A partir de Felipe II se comienzan a nombrar letrados para presidir la Chancillería de Granada y con Carlos II Ilegan los primeros letrados a Valladolid. A partir de Fernando VI desaparecerán los clérigos de estos cargos.

38. Se incluyen Capitanes Generales, Tenientes Generales, Brigadieres y Jefes de Escuadra. Entendemos por origen social la profesión o rango (en el caso de ser nobles titulados) de sus padres, dado que en el siglo XVIII la carrera militar en la Armada se solía iniciar en la adolescencia como guardiamarinas. El grueso de las referencias biográficas se han tomado, entre otras fuentes, de PAVÍA, F. de P., Galería biográfica de los generales de la Marina, Madrid, 1873.

39. Véanse una serie de trabajos recientes en ARANDA, F. J. (coord.), Letrados, juristas y burócratas en la España moderna, Cuenca, Universidad de Castilla-La Mancha, 2005.

40. Las listas de los regentes pueden verse en MOLAS RIBALTA, P., "Las audiencias borbónicas de la corona de Aragón. Aportación a su estudio", Estudis, n 5, 1976, pp. 59124. 
TABLA 31. Origen social de los presidentes de las chancillerías.

\begin{tabular}{|l|c|c|c|c|c|c|c|c|c|c|}
\hline \multirow{2}{*}{ Reinado } & \multicolumn{2}{|c|}{ BUROCRACIA } & \multicolumn{2}{c|}{ MILITARES } & \multicolumn{2}{c|}{$\begin{array}{c}\text { ALTA } \\
\text { NOBLEZA }\end{array}$} & \multicolumn{2}{c|}{$\begin{array}{c}\text { ÉLITES } \\
\text { LOCALES }\end{array}$} & \multicolumn{2}{c|}{ CLERO } \\
\cline { 2 - 13 } & $\mathbf{N}^{\mathbf{0}}$ & $\mathbf{\%}$ & $\mathbf{N}^{\mathbf{0}}$ & $\mathbf{\%}$ & $\mathbf{N}^{\mathbf{0}}$ & $\mathbf{\%}$ & $\mathbf{N}^{\mathbf{0}}$ & $\mathbf{\%}$ & $\mathbf{N}^{\mathbf{0}}$ & $\mathbf{\%}$ \\
\hline $1500-1515$ & 0 & 0 & 0 & 0 & 0 & 0 & 0 & 0 & 6 & 100 \\
\hline Carlos I & 0 & 0 & 0 & 0 & 0 & 0 & 0 & 0 & 15 & 100 \\
\hline Felipe II & 5 & 28 & 0 & 0 & 0 & 0 & 0 & 0 & 13 & 72 \\
\hline Felipe III & 2 & 18 & 0 & 0 & 0 & 0 & 0 & 0 & 9 & 82 \\
\hline Felipe IV & 4 & 27 & 0 & 0 & 1 & 7 & 0 & 0 & 10 & 67 \\
\hline Carlos II & 11 & 65 & 0 & 0 & 0 & 0 & 0 & 0 & 8 & 35 \\
\hline Felipe V & 16 & 73 & 0 & 0 & 3 & 14 & 0 & 0 & 3 & 14 \\
\hline Fernando VI & 6 & 86 & 0 & 0 & 1 & 14 & 0 & 0 & 0 & 0 \\
\hline Carlos III & 15 & 94 & 0 & 0 & 1 & 6 & 0 & 0 & 0 & 0 \\
\hline Carlos IV & 8 & 100 & 0 & 0 & 0 & 0 & 0 & 0 & 0 & 0 \\
\hline TOTAL & $\mathbf{6 5}$ & $\mathbf{4 8}$ & $\mathbf{0}$ & $\mathbf{0}$ & $\mathbf{6}$ & $\mathbf{5}$ & $\mathbf{0}$ & $\mathbf{0}$ & $\mathbf{6 4}$ & $\mathbf{4 7}$ \\
\hline
\end{tabular}

Los Consejos, excluidos el de Guerra y el de Estado, tenían todos una estructura organizativa parecida, pero notorias diferencias en la forma de seleccionar a su personal, incluidos sus presidentes ${ }^{41}$. Las presidencias de Inquisición y Cruzada estaban reservadas a clérigos y una situación parecida ocurría con los nobles titulados en el Consejo de Órdenes, que copan un 75\% de las designaciones. En el resto, la pugna se estableció entre los letrados y los nobles: si exceptuamos a los tres consejos antes citados, los burócratas controlaron un $42 \%$ de las presidencias y los nobles titulados un 33\%.

TABLA 32. Origen social de los presidentes de los consejos $^{42}$.

\begin{tabular}{|l|c|c|c|c|c|c|c|c|c|c|}
\hline \multirow{3}{*}{ Virreinato } & \multicolumn{3}{|c|}{ BUROCRACIA } & \multicolumn{2}{c|}{ MILITARES } & \multicolumn{2}{c|}{$\begin{array}{c}\text { ALTA } \\
\text { NOBLEZA }\end{array}$} & \multicolumn{2}{c|}{$\begin{array}{c}\text { ÉLITES } \\
\text { LOCALES }\end{array}$} & \multicolumn{2}{c|}{ CLERO } \\
\cline { 2 - 13 } & $\mathbf{N}^{\mathbf{0}}$ & $\mathbf{\%}$ & $\mathbf{N}^{\mathbf{0}}$ & $\mathbf{\%}$ & $\mathbf{N}^{\mathbf{0}}$ & $\mathbf{\%}$ & $\mathbf{N}^{\mathbf{0}}$ & $\mathbf{\%}$ & $\mathbf{N}^{\mathbf{0}}$ & $\mathbf{\%}$ \\
\hline Inquisición & 0 & 0 & 0 & 0 & 0 & 0 & 0 & 0 & 42 & 100 \\
\hline Italia & 7 & 22 & 0 & 0 & 20 & 62 & 0 & 0 & 5 & 16 \\
\hline Aragón & 19 & 63 & 0 & 0 & 8 & 27 & 0 & 0 & 3 & 10 \\
\hline
\end{tabular}

41. Véase un recorrido general y la relación de los altos dignatarios en ESCUDERO, J. A., Los hombres de la monarquía universal, Madrid, 2011.

42. Los nombres de los presidentes pueden obtenerse en ARTOLA, M. (dir.), Enciclopedia de la Historia de España, Vol. 6, pp. 1.081 y ss. 


\begin{tabular}{|l|c|c|c|c|c|c|c|c|c|c|}
\hline \multirow{2}{*}{ Virreinato } & \multicolumn{2}{|c|}{ BUROCRACIA } & \multicolumn{2}{c|}{ MILITARES } & \multicolumn{2}{c|}{$\begin{array}{c}\text { ALTA } \\
\text { NOBLEZA }\end{array}$} & \multicolumn{2}{c|}{$\begin{array}{c}\text { ÉLITES } \\
\text { LOCALES }\end{array}$} & \multicolumn{2}{c|}{ CLERO } \\
\cline { 2 - 12 } & $\mathbf{N}^{\mathbf{0}}$ & $\mathbf{\%}$ & $\mathbf{N}^{\mathbf{0}}$ & $\mathbf{\%}$ & $\mathbf{N}^{\mathbf{0}}$ & $\mathbf{\%}$ & $\mathbf{N}^{\mathbf{0}}$ & $\mathbf{\%}$ & $\mathbf{N}^{\mathbf{0}}$ & $\mathbf{\%}$ \\
\hline Indias & 13 & 31 & 1 & 2 & 24 & 57 & 0 & 0 & 4 & 10 \\
\hline Hacienda & 47 & 63 & 1 & 1 & 13 & 17 & 5 & 7 & 9 & 12 \\
\hline Castilla & 17 & 26 & 2 & 3 & 16 & 25 & 0 & 0 & 30 & 46 \\
\hline Órdenes & 8 & 21 & 1 & 2 & 28 & 75 & 0 & 0 & 0 & 0 \\
\hline Cruzada & 0 & 0 & 0 & 0 & 0 & 0 & 0 & 0 & 20 & 100 \\
\hline TOTAL & $\mathbf{1 1 1}$ & $\mathbf{3 2}$ & $\mathbf{5}$ & $\mathbf{1}$ & $\mathbf{1 0 9}$ & $\mathbf{3 1}$ & $\mathbf{5}$ & $\mathbf{2}$ & $\mathbf{1 1 3}$ & $\mathbf{3 3}$ \\
\hline
\end{tabular}

Si observamos el cuadro siguiente, comprobamos que las máximas cotas de poder las alcanzaron los letrados en la época de Felipe II -un 57\%-, lo que es coincidente con otros procesos ya conocidos que afectaron a los graduados universitarios $^{43}$. Los nobles, como sucede en casi todos los ámbitos, tuvieron las mayores cotas de poder durante el siglo XVII, especialmente en el reinado de Carlos II -un $48 \%$-. Los clérigos, por su parte, no dejaron de perder peso durante los siglos XVI y XVII. La evaluación de las presidencias del siglo XVIII ha de hacerse tomando en consideración la pérdida de poder efectivo de los Consejos frente a las Secretarías de Estado, que asumieron el grueso de sus funciones políticas.

TABLA 33. Origen social de los presidentes de los consejos $^{44}$.

\begin{tabular}{|l|c|c|c|c|c|c|c|c|c|c|}
\hline \multirow{2}{*}{ Reinado } & \multicolumn{2}{|c|}{ BUROCRACIA } & \multicolumn{2}{c|}{ MILITARES } & \multicolumn{2}{c|}{$\begin{array}{c}\text { ALTA } \\
\text { NOBLEZA }\end{array}$} & \multicolumn{2}{c|}{$\begin{array}{c}\text { ÉLITES } \\
\text { LOCALES }\end{array}$} & \multicolumn{2}{c|}{ CLERO } \\
\cline { 2 - 13 } & $\mathbf{N}^{\mathbf{0}}$ & $\mathbf{\%}$ & $\mathbf{N}^{\mathbf{0}}$ & $\mathbf{\%}$ & $\mathbf{N}^{\mathbf{0}}$ & $\mathbf{\%}$ & $\mathbf{N}^{\mathbf{0}}$ & $\mathbf{\%}$ & $\mathbf{N}^{\mathbf{0}}$ & $\mathbf{\%}$ \\
\hline $1500-1515$ & 2 & 18 & 1 & 9 & 1 & 9 & 0 & 0 & 7 & 63 \\
\hline Carlos I & 13 & 34 & 0 & 0 & 8 & 21 & 0 & 0 & 17 & 44 \\
\hline Felipe II & 28 & 57 & 0 & 0 & 10 & 16 & 0 & 0 & 21 & 35 \\
\hline Siglo XVI & $\mathbf{4 3}$ & $\mathbf{3 9}$ & $\mathbf{1}$ & $\mathbf{1}$ & $\mathbf{1 9}$ & $\mathbf{1 7}$ & $\mathbf{0}$ & $\mathbf{0}$ & $\mathbf{4 5}$ & $\mathbf{4 1}$ \\
\hline Felipe III & 10 & 26 & 0 & 0 & 18 & 47 & 0 & 0 & 10 & 26 \\
\hline Felipe IV & 19 & 31 & 0 & 0 & 26 & 42 & 0 & 0 & 17 & 27 \\
\hline Carlos II & 19 & 31 & 0 & 0 & 29 & 48 & 0 & 0 & 12 & 20 \\
\hline Siglo XVII & $\mathbf{4 8}$ & $\mathbf{3 0}$ & $\mathbf{0}$ & $\mathbf{0}$ & $\mathbf{7 3}$ & $\mathbf{4 6}$ & $\mathbf{0}$ & $\mathbf{0}$ & $\mathbf{3 9}$ & $\mathbf{2 4}$ \\
\hline
\end{tabular}

43. Véase CARABIAS TORRES, A. M. Colegios Mayores: Centros de poder. Los Colegios Mayores de Salamanca durante el siglo XVI, Salamanca, 1986, 3 vols.

44. Se incluyen los Consejos de Indias, Hacienda, Castilla, Inquisición, Aragón, Órdenes, Cruzada e Italia. En los de Estado, Guerra, Flandes y Portugal el Presidente era el propio rey. 


\begin{tabular}{|c|c|c|c|c|c|c|c|c|c|c|}
\hline \multirow{2}{*}{ Reinado } & \multicolumn{2}{|c|}{ BUROCRACIA } & \multicolumn{2}{|c|}{ MILITARES } & \multicolumn{2}{|c|}{$\begin{array}{c}\text { ALTA } \\
\text { NOBLEZA }\end{array}$} & \multicolumn{2}{|c|}{$\begin{array}{c}\text { ÉLITES } \\
\text { LOCALES }\end{array}$} & \multicolumn{2}{|c|}{ CLERO } \\
\hline & $\mathbf{N}^{\mathbf{o}}$ & $\%$ & $\mathrm{~N}^{\mathrm{o}}$ & $\%$ & $\mathbf{N}^{\mathbf{o}}$ & $\%$ & $\mathbf{N}^{\mathbf{o}}$ & $\%$ & $\mathbf{N}^{\mathbf{o}}$ & $\%$ \\
\hline Felipe V & 12 & 22 & 1 & 1 & 17 & 32 & 5 & 9 & 18 & 33 \\
\hline Fernando VI & 1 & 11 & 0 & 0 & 3 & 33 & 0 & 0 & 5 & 55 \\
\hline Carlos III & 6 & 46 & 0 & 0 & 4 & 30 & 0 & 0 & 3 & 23 \\
\hline Carlos IV & 1 & 11 & 3 & 33 & 2 & 22 & 0 & 0 & 3 & 33 \\
\hline Siglo XVIII & 20 & 24 & 4 & 5 & 26 & 31 & 5 & 6 & 29 & 34 \\
\hline
\end{tabular}

La construcción de todo este entramado institucional permitió a la Universidad vivir una época gloriosa en el siglo XVI, con la fundación masiva de nuevas universidades -que pasan de ser 6 en 1474 a 35 en 1600, un crecimiento del 583\% - y un aumento generalizado del alumnado. La fiebre fundacional cesará de forma brusca en el reinado de Fernando VI y en toda la segunda mitad del XVIII no se funda ninguna universidad ni colegio universitario, salvo la refundación del Colegio Imperial como Reales Estudios de San Isidro, concediendo rango universitario a sus títulos, tras la expulsión de los Jesuitas.

La Universidad jugó un papel central en los grandes cambios sociales que se produjeron durante los siglos XVI y XVII, pues fue la principal vía que tuvieron a su disposición las élites locales hidalgas para acceder al poder político y, más adelante, a las filas de la nobleza titulada. La alta nobleza tuvo una presencia puramente testimonial en las aulas universitarias, muy inferior al 1\% en Salamanca durante los siglos XVI y XVII ${ }^{45}$, y prácticamente desapareció por completo desde mediados de este siglo. Pero pese a esta realidad, las universidades trasladaron a su seno las desigualdades sociales que existían entre sus alumnos y utilizando para ello, paradójicamente, unas entidades, los colegios mayores, que habían sido fundados casi todos para permitir acceder a la Universidad a los alumnos pobres. Si observamos la información aportada por Dámaso de Lario sobre el origen de los estudiantes de los 5 colegios mayores, observamos como, entre mediados del XVI y mediados del XVII la presencia de la alta nobleza se triplica entre el primer y el último periodo, mientras que la de los

45. En la cala que hizo L. E. Rodríguez San Pedro, el porcentaje mayor se da en 1664 con un 0,6\%. Según Kagan, entre 1550 y 1699 pasaron por Salamanca 126 hijos de nobles titulados. En su opinión, sólo entre el 5 y el 10\% de los hijos de los aristócratas pasaban, siquiera temporalmente, por alguna universidad, lo habitual era que fuesen educados en casa. Cfr. KAGAN, R. L., op. cit., pp. 226-229. En cualquier caso, aunque fuesen pocos los estudiantes, su presencia entre los cargos dirigentes de la Universidad fue, en algunos momentos, hegemónica. 
colegiales realmente humildes desciende significativamente. Los colegios, por tanto, se aristocratizan cada vez más, aunque puede observarse como las élites locales hidalgas no reducen sus efectivos, antes bien los aumentan a lo largo del periodo.

TABLA 34. Origen social de los colegiales mayores (en \% $)^{46}$.

\begin{tabular}{|l|c|c|c|c|}
\hline \multicolumn{1}{|c|}{ Periodo } & $\begin{array}{c}\text { ALTA } \\
\text { NOBLEZA }\end{array}$ & $\begin{array}{c}\text { SEÑORES } \\
\text { VASALLOS }\end{array}$ & HIDALGOS & $\begin{array}{c}\text { ORIGEN } \\
\text { HUMILDE }\end{array}$ \\
\hline $1560-1574$ & 3 & 2 & 49 & 46 \\
\hline $1575-1589$ & 5 & 7 & 40 & 48 \\
\hline $1590-1604$ & 6 & 11 & 39 & 46 \\
\hline Siglo XVI & $\mathbf{5}$ & 7 & $\mathbf{4 2}$ & $\mathbf{4 6}$ \\
\hline $1605-1619$ & 11 & 5 & 53 & 30 \\
\hline $1620-1634$ & 7 & 2 & 38 & 53 \\
\hline $1635-1650$ & 12 & 8 & 52 & 27 \\
\hline Siglo XVII & $\mathbf{1 0}$ & $\mathbf{5}$ & $\mathbf{4 8}$ & $\mathbf{3 7}$ \\
\hline TOTAL & $\mathbf{8}$ & $\mathbf{6}$ & $\mathbf{4 5}$ & $\mathbf{4 1}$ \\
\hline
\end{tabular}

Los colegios mayores, profundamente corporativistas y con una calidad académica más que dudosa, tuvieron un efecto pernicioso sobre el prestigio social de los graduados universitarios, pero ello no les impidió, hasta las reformas del XVIII, controlar amplias esferas de la burocracia civil. La presencia de colegiales en las instituciones y su curriculum posterior es más que significativa de este fenómeno, Ilegando a copar más del 60\% de los altos cargos de los consejos durante la segunda mitad del XVII.

El resultado fue que, a partir del XVII, las universidades, para quienes no podían acceder a un Colegio Mayor, perdieron atractivo como mecanismo de ascenso social y ello provocó una caída brusca del número de estudiantes, que ya no se recuperaría en todo el Antiguo Régimen, pasando de unos 20.000 alumnos a finales del XVI a unos 5.000 a mediados del XVIII ${ }^{47}$. Si observamos más en detalle un caso, lo ocurrido en la Universidad de Salamanca, una de las más afectadas por la caída del alumnado a partir del siglo XVII, que pasó de tener unos 6.000 alumnos a finales del XVI a menos de

46. Los datos, reelaborados por mi, proceden de LARIO, D. de, "Origen social de los colegiales", en OLMOS, V. S. (coord.), Doctores y escolares, Valencia, 1998, Vol. I, p. 334.

47. Los datos proceden de KAGAN, R. L., Universidad y sociedad en la España Moderna, Madrid, Tecnos, 1981, p. 244. 
1.500 en 1784, una reducción del 75\%, vemos como los típicos estudios que cursaban los burócratas, derecho canónico y civil, están entre los más afectados por la reducción de la matrícula.

TABLA 35. Evolución de la matrícula en la Universidad de Salamanca ${ }^{48}$.

\begin{tabular}{|c|c|c|c|c|c|c|c|c|c|c|c|c|}
\hline \multirow{2}{*}{ Fecha } & \multicolumn{2}{|c|}{ Gramática } & \multicolumn{2}{c|}{ Cánones } & \multicolumn{2}{c|}{ Leyes } & \multicolumn{2}{c|}{ Teología } & \multicolumn{2}{|c|}{ Medicina } & \multicolumn{2}{|c|}{ Artes } \\
\cline { 2 - 14 } & $\mathbf{N}^{\mathbf{0}}$ & $\%$ & $\mathbf{N}^{\mathbf{0}}$ & $\%$ & $\mathbf{N}^{\mathbf{0}}$ & $\%$ & $\mathbf{N}^{\mathbf{0}}$ & $\%$ & $\mathbf{N}^{\mathbf{0}}$ & $\%$ & $\mathbf{N}^{\mathbf{0}}$ & $\%$ \\
\hline 1555 & 1.688 & 100 & 1.063 & 100 & 636 & 100 & 420 & 100 & 157 & 100 & 706 & 100 \\
\hline 1585 & 893 & 53 & 2.939 & 276 & 686 & 108 & 571 & 136 & 194 & 124 & 924 & 131 \\
\hline 1595 & 448 & 27 & 2.776 & 261 & 768 & 121 & - & - & 208 & 132 & 693 & 98 \\
\hline 1605 & 331 & 20 & 2.386 & 224 & 314 & 49 & 343 & 82 & 164 & 104 & 627 & 89 \\
\hline 1614 & 434 & 26 & 2.880 & 271 & 276 & 43 & 770 & 183 & 184 & 117 & 601 & 85 \\
\hline 1634 & 328 & 19 & 2.464 & 232 & 236 & 37 & 407 & 97 & 106 & 68 & 362 & 51 \\
\hline 1664 & 204 & 12 & 1.163 & 109 & 146 & 23 & 179 & 43 & 58 & 37 & 221 & 31 \\
\hline 1684 & 82 & 5 & 631 & 59 & 96 & 15 & 94 & 22 & 45 & 29 & 175 & 25 \\
\hline 1714 & 92 & 5 & 292 & 27 & 177 & 28 & 57 & 14 & 35 & 22 & 108 & 15 \\
\hline 1734 & 180 & 11 & 129 & 12 & 213 & 33 & 57 & 14 & 21 & 13 & 331 & 47 \\
\hline 1764 & 49 & 3 & 149 & 14 & 271 & 43 & 80 & 19 & 43 & 27 & 313 & 44 \\
\hline 1784 & 34 & 2 & 147 & 14 & 170 & 27 & 250 & 60 & 13 & 8 & 350 & 50 \\
\hline
\end{tabular}

La caída de la matrícula afectó muy especialmente a los llamados manteístas, alumnos que no podían acceder a los colegios universitarios, reduciendo a menos de la mitad su presencia relativa durante los siglos XVII y XVIII -hasta las reformas de Carlos III tendentes a reducir la influencia de los colegios- $y$, paralelamente, la universidad se clericaliza, aumentando considerablemente la presencia relativa de miembros de las órdenes religiosas en sus aulas hasta las mencionadas reformas.

48. La información reelaborada por mi, procede, para el siglo XVI, de KAMEN, R. L., Universidad y sociedad, op. cit., y para los siglos XVII y XVIII de RODRÍGUEZ SAN PEDRO, L. E. y otros, "Declive y regionalización de la matrícula salmantina en los siglos XVI y XVII", Studia Historica, Vol. III, nº 3, 1985, pp. 143-163. 
TABLA 36. Evolución de colegiales y manteístas en la Universidad de Salamanca (en \%) ${ }^{49}$.

\begin{tabular}{|c|c|c|c|}
\hline Periodo & $\begin{array}{c}\text { COLEGIALES } \\
\text { SECULARES }\end{array}$ & $\begin{array}{c}\text { COLEGIALES } \\
\text { REGULARES }\end{array}$ & MANTEÍSTAS \\
\hline $1614-15$ & 4,9 & 8,1 & 87 \\
\hline $1634-35$ & 4,7 & 8,1 & 87,7 \\
\hline $1664-65$ & 9,4 & 19,4 & 71,2 \\
\hline $1684-85$ & 13,7 & 30,2 & 51,6 \\
\hline $1714-15$ & 21,3 & 42,3 & 31,6 \\
\hline $1734-35$ & 11,5 & 42,5 & 37,4 \\
\hline $1764-65$ & 16,8 & 42,5 & 41,5 \\
\hline $1784-85$ & 9 & 24 & 66,8 \\
\hline
\end{tabular}

Ya en el siglo XVIII, el desprestigio de la Universidad propició que cada vez con mayor decisión se le concediese más crédito al mérito que al título y que surgiesen, apoyados por la Corona muy a menudo, toda clase de centros formativos que escapaban al control del clero, de las universidades y, por supuesto, de los Colegios Mayores -aunque éstos no se clausuraron definitivamente hasta 1798-. Estos nuevos centros educativos, destinados, como expresamente decían los ilustrados, a las enseñanzas útiles, irían desde la formación de artesanos hasta la de ingenieros, boticarios o cirujanos, incluso se dedicarán a la enseñanza práctica de la medicina y del derecho, estudios tradicionalmente controlados por la universidad. El panorama de este tipo de escuelas marca dos épocas bien distintas, una primera, los siglos XVI y XVII, donde, salvo alguna intervención de la Corona en campos como la formación de militares para el Ejército y de pilotos para la Armada y unos pocos casos procedentes de la sociedad civil ${ }^{50}$, el grueso de las fundaciones son eclesiásticas y dedicadas en su mayoría a la formación de frailes -ya vimos antes como además se abrieron más de 120 seminarios en esta época-. La segunda época, que se anuncia con Felipe $V$, tiene como gran novedad la entrada en escena de la sociedad civil, organizada en torno a juntas de comercio, academias y sociedades económicas, que serán las responsables de la apertura de más de 170 escuelas especiales durante el siglo XVIII, casi un $60 \%$ de las que he podido documentar en esta época. La nueva educación, como defendían públicamente los ilustrados, se hace al margen de

49. Los datos proceden de RODRÍGUEZ SAN PEDRO, L. E., art. cit., p. 146.

50. La presencia privada en la fundación de escuelas especiales se reduce en 200 años a un par de escuelas para la formación de marineros que abrió el Consulado de Bilbao a principios del XVI. una Escuela de Pintura que abrieron en Sevilla un grupo de artistas en el XVII y, sobre todo, las llamadas maestranzas de caballería, éstas con un perfil docente bien dudoso. 
las fórmulas educativas tradicionales y dejando fuera a la Iglesia, que pasará de controlar un $65 \%$ de las fundaciones en los siglos XVI y XVII a sólo un $15 \%$ en el XVIII.

TABLA 37. Fundación de escuelas especiales.

\begin{tabular}{|l|c|c|c|c|c|c|}
\hline \multirow{2}{*}{ Reinado } & \multicolumn{2}{|c|}{ CORONA } & \multicolumn{2}{c|}{ IGLESIA } & \multicolumn{2}{c|}{$\begin{array}{c}\text { SOCIEDAD } \\
\text { CIVIL }\end{array}$} \\
\cline { 2 - 7 } & $\mathbf{N}^{\mathbf{0}}$ & $\mathbf{\%}$ & $\mathbf{N}^{\mathbf{0}}$ & $\mathbf{\%}$ & $\mathbf{N}^{\mathbf{0}}$ & $\mathbf{\%}$ \\
\hline $1500-1515$ & 1 & 20 & 2 & 40 & 2 & 40 \\
\hline Carlos I & 3 & 14 & 18 & 86 & 0 & 0 \\
\hline Felipe II & 10 & 38 & 14 & 54 & 2 & 8 \\
\hline Felipe III & 4 & 25 & 11 & 69 & 1 & 6 \\
\hline Felipe IV & 3 & 37 & 4 & 50 & 1 & 12 \\
\hline Carlos II & 9 & 32 & 15 & 54 & 4 & 14 \\
\hline Siglos XVI-XVII & $\mathbf{3 0}$ & $\mathbf{2 6}$ & $\mathbf{7 4}$ & $\mathbf{6 5}$ & $\mathbf{1 0}$ & $\mathbf{9}$ \\
\hline Felipe V & 18 & 34 & 19 & 36 & 16 & 30 \\
\hline Fernando VI & 11 & 24 & 7 & 16 & 27 & 60 \\
\hline Carlos III & 38 & 27 & 10 & 7 & 95 & 66 \\
\hline 1789-1799 & 19 & 29 & 9 & 14 & 38 & 58 \\
\hline Siglo XVIII & $\mathbf{8 6}$ & $\mathbf{2 8}$ & $\mathbf{4 5}$ & $\mathbf{1 5}$ & $\mathbf{1 7 6}$ & $\mathbf{5 7}$ \\
\hline TOTAL & $\mathbf{1 1 6}$ & $\mathbf{2 8}$ & $\mathbf{1 0 9}$ & $\mathbf{2 7}$ & $\mathbf{1 8 6}$ & $\mathbf{4 5}$ \\
\hline
\end{tabular}

Otro grupo de burócratas con enorme poder en la Corte era el constituido por los secretarios. Los secretarios de los Austrias, muy numerosos dado que había al menos uno por Consejo, eran siempre burócratas con larga experiencia previa en puestos inferiores de la Administración, no eran cargos por tanto que la alta nobleza considerase digno de su rango ocupar. Un ejemplo, los secretarios del Consejo de Estado eran los más prestigiosos de todos, pues bien, aun así, entre los 60 designados durante los siglos XVI y XVII sólo hubo un par de nobles, alemanes, entre 1522 y 1524. Las secretarías borbónicas introdujeron, sin embargo, un cambio cualitativo importante: tenían poder efectivo, de ahí que hubiese nobles dispuestos a ejercerlas, incluso alguno perteneciente a los grandes linajes bajomedievales ${ }^{51}$. Pero, pese a ello, fueron personas con amplia experiencia burocrática quienes controlaron la mayoría de los nombramientos

51. Véase el clásico de ESCUDERO, J. A., El origen del Consejo de Ministros en España, Madrid, 1979, 2 vols.; y un repaso más reciente en LÓPEZ-CORDÓN, M. V., "Secretarios y secretarías en la Edad Moderna: de las manos del príncipe a relojeros de la monarquía", Studia historica, Historia Moderna, nº 15, 1996, pp. 107-131. 
-un 56\% exactamente-. Es interesante también observar que buena parte de estos secretarios no son licenciados universitarios, sino personas que habían ido ascendiendo por los distintos escalafones de la burocracia y sin otra escuela que la experiencia -el caso de Ensenada sería paradigmático-. También tienen una presencia significativa los militares, gracias sobre todo a las secretarías de Guerra y de Marina.

TABLA 38. Origen social de los secretarios de estado por reinado ${ }^{52}$.

\begin{tabular}{|l|c|c|c|c|c|c|c|c|c|c|}
\hline \multirow{2}{*}{ Reinado } & \multicolumn{3}{|c|}{ BUROCRACIA } & \multicolumn{2}{|c|}{ MILITARES } & \multicolumn{2}{c|}{$\begin{array}{c}\text { ALTA } \\
\text { NOBLEZA }\end{array}$} & \multicolumn{2}{c|}{$\begin{array}{c}\text { ÉLITES } \\
\text { LOCALES }\end{array}$} & \multicolumn{2}{c|}{ CLERO } \\
\cline { 2 - 13 } & $\mathbf{N}^{\mathbf{0}}$ & $\mathbf{\%}$ & $\mathbf{N}^{\mathbf{0}}$ & $\mathbf{\%}$ & $\mathbf{N}^{\mathbf{0}}$ & $\mathbf{\%}$ & $\mathbf{N}^{\mathbf{0}}$ & $\mathbf{\%}$ & $\mathbf{N}^{\mathbf{0}}$ & $\mathbf{\%}$ \\
\hline Felipe V & 18 & 69 & 2 & 7 & 5 & 17 & 0 & 0 & 1 & 3 \\
\hline $\begin{array}{l}\text { Fernando } \\
\text { VI }\end{array}$ & 1 & 17 & 3 & 50 & 2 & 33 & 0 & 0 & 0 & 0 \\
\hline Carlos III & 4 & 36 & 3 & 27 & 4 & 36 & 0 & 0 & 0 & 0 \\
\hline $\begin{array}{l}1789- \\
1799\end{array}$ & 8 & 57 & 4 & 28 & 2 & 14 & 0 & 0 & 0 & 0 \\
\hline TOTAL & $\mathbf{3 1}$ & $\mathbf{5 6}$ & $\mathbf{1 2}$ & $\mathbf{2 2}$ & $\mathbf{1 1}$ & $\mathbf{2 0}$ & $\mathbf{0}$ & $\mathbf{0}$ & $\mathbf{1}$ & $\mathbf{2}$ \\
\hline
\end{tabular}

Los embajadores eran también personas cercanas al monarca y, por tanto, puestos apetecidos por la alta nobleza, el alto clero y los burócratas poderosos. Se distinguen con claridad en este caso tres periodos bien diferenciados. El primero, coincidente con el siglo XVI, en el que las embajadas no tienen -salvo la de Roma a partir de Felipe II- una estructura permanente, es decir, que cada embajador era enviado a una Corte para tratar un asunto concreto, de tal manera que si no había asuntos que tratar, la embajada desaparecía, y si había varios, pues terminaban siendo designados varios embajadores simultáneamente. La diversidad de asuntos a tratar aconsejaba a menudo el envío de personas "especializadas", de ahí la importante presencia de burócratas y de clérigos, a costa de los nobles titulados. A lo largo del siglo XVII esta situación se mantiene en cierta medida, aunque ya no es tan habitual encontrar a varios embajadores a la vez en un mismo destino. Lo más característico de este siglo es que la figura del embajador obtiene un alto grado de reconocimiento institucional en las distintas cortes y ello recomienda el envío de nobles titulados, que llegarán a suponer más del 80\% en algún periodo. En el siglo XVIII las embajadas se hacen permanentes y se dotan de una infraestructura profesionalizada, y cada vez con mayor frecuencia, estos burócratas terminan siendo designados como embajadores a costa de los nobles titulados, que a duras penas conseguirán ocupar el 45\% de las embajadas.

52. La lista de intendentes procede de ARTOLA, M. (dir.), Enciclopedia de Historia de España, Vol. 6, pp. 1.095 y ss. 
TABLA 39. Origen social de los embajadores ${ }^{53}$.

\begin{tabular}{|c|c|c|c|c|c|c|c|c|c|c|}
\hline \multirow[t]{2}{*}{ Reinado } & \multicolumn{2}{|c|}{ BUROCRACIA } & \multicolumn{2}{|c|}{ MILITARES } & \multicolumn{2}{|c|}{$\begin{array}{c}\text { ALTA } \\
\text { NOBLEZA }\end{array}$} & \multicolumn{2}{|c|}{$\begin{array}{c}\text { ÉLITES } \\
\text { LOCALES }\end{array}$} & \multicolumn{2}{|c|}{ CLERO } \\
\hline & $\mathbf{N}^{0}$ & $\%$ & $\mathbf{N}^{o}$ & $\%$ & $\mathbf{N}^{0}$ & $\%$ & $\mathbf{N}^{0}$ & $\%$ & $\mathbf{N}^{0}$ & $\%$ \\
\hline $1500-1515$ & 5 & 62 & 0 & 0 & 1 & 12 & 0 & 0 & 2 & 25 \\
\hline Carlos I & 33 & 33 & 6 & 6 & 43 & 43 & 0 & 0 & 17 & 17 \\
\hline Felipe II & 18 & 35 & 6 & 12 & 15 & 29 & 3 & 6 & 9 & 18 \\
\hline Siglo XVI & 56 & 35 & 12 & 8 & 59 & 37 & 3 & 2 & 28 & 18 \\
\hline Felipe III & 2 & 9 & 1 & 4 & 18 & 82 & 0 & 0 & 1 & 4 \\
\hline Felipe IV & 8 & 14 & 4 & 7 & 38 & 69 & 0 & 0 & 5 & 9 \\
\hline Carlos II & 6 & 12 & 4 & 8 & 32 & 68 & 0 & 0 & 5 & 10 \\
\hline Siglo XVII & 16 & 13 & 9 & 7 & 88 & 71 & $\mathbf{0}$ & $\mathbf{0}$ & 11 & 9 \\
\hline Felipe V & 13 & 24 & 6 & 11 & 28 & 51 & 1 & 1 & 6 & 11 \\
\hline Fernando VI & 9 & 29 & 3 & 9 & 17 & 54 & 0 & 0 & 2 & 6 \\
\hline Carlos III & 40 & 42 & 13 & 14 & 41 & 43 & 0 & 0 & 0 & 0 \\
\hline 1789-1799 & 20 & 66 & 3 & 10 & 7 & 23 & 0 & 0 & 0 & 0 \\
\hline Siglo XVIII & 82 & 39 & 25 & 12 & 93 & 45 & $\mathbf{0}$ & $\mathbf{0}$ & 8 & 4 \\
\hline TOTAL & 154 & 31 & 46 & 9 & 240 & 48 & 4 & 1 & 47 & 9 \\
\hline
\end{tabular}

Los gobiernos territoriales -gobernaciones, corregimientos, capitanías generales, virreinatos, etc.-, supusieron durante el Antiguo Régimen una oferta numerosísima de puestos disponibles, especialmente en los siglos XVI y XVII, cuando a los cargos peninsulares, africanos y americanos se le sumaban los de las posesiones europeas. Esta abrumadora oferta de puestos de gobierno ha de tenerse en cuenta a la hora de evaluar los datos, especialmente en los cargos menos apetecibles, los ubicados en las colonias ${ }^{54}$.

Si analizamos el perfil social de los gobernadores de Indias observamos que la alta nobleza sólo tiene una presencia significativa en las gobernaciones más

53. Se han considerado las embajadas en Austria-Sacro Imperio, Génova, Francia, Santa Sede, Portugal, Rusia, Suecia, Turquía, Venecia, Inglaterra, Prusia, Toscana, Suiza, Nápoles, Parma, Sajonia, Dinamarca y Polonia. Véase OCHOA BRUN, M. A., Embajadas y embajadores en la historia de España, Madrid, Aguilar, 2002; y OZANAM, D., Les diplomates espagnols du XVIIle siècle: introduction et répertoire biographique (1700-1808), Madrid, Casa de Velázquez-Maison des Pays Ibériques, 1998.

54. - Referencias biográficas abundantes sobre los gobernadores de Indias en SZASZDI, I. (coord.), Historia de las gobernaciones atlánticas en el Nuevo Mundo, Universidad de Puerto Rico, 2011; y en BARRIOS, F. (coord.), El gobierno de un mundo. Virreinatos y Audiencias en América Hispánica, Cuenca, Universidad de Castilla-La Mancha, 2004. 
lucrativas, como Cuba, La Española o Panamá, y en las más seguras, como Bogotá o Quito, e incluso en éstas apenas se supera el 10\% de nobles titulados. Chile, el Flandes de Indias, es un caso especial, pues la precariedad de la presencia española por la resistencia de los araucanos o mapuches forzará en determinados momentos el despliegue de importantes contingentes militares y con ellos la presencia de nobles titulados Ilegará hasta el 13\%

El proceso social más relevante en las gobernaciones indianas fue la sustitución de los gobernadores burócratas, normalmente titulados universitarios, por militares. Los primeros alcanzan su cénit en el reinado de Felipe II -un 55\%-, pero a partir de entonces su presencia irá disminuyendo conforme aumenta la de los militares, y el proceso se intensificará todavía más en el siglo XVIII, cuando los militares llegarán a suponer un $84 \%$ de los gobernadores a finales de siglo.

TABLA 40. Origen social de los gobernadores de Indias.

\begin{tabular}{|c|c|c|c|c|c|c|c|c|c|c|}
\hline \multirow[t]{2}{*}{ Reinado } & \multicolumn{2}{|c|}{ BUROCRACIA } & \multicolumn{2}{|c|}{ MILITARES } & \multicolumn{2}{|c|}{$\begin{array}{c}\text { ALTA } \\
\text { NOBLEZA }\end{array}$} & \multicolumn{2}{|c|}{$\begin{array}{c}\text { ÉLITES } \\
\text { LOCALES }\end{array}$} & \multicolumn{2}{|c|}{ CLERO } \\
\hline & $\mathbf{N}^{0}$ & $\%$ & $\mathrm{~N}^{0}$ & $\%$ & $\mathrm{~N}^{\mathrm{o}}$ & $\%$ & $N^{0}$ & $\%$ & $\mathrm{~N}^{\mathbf{0}}$ & $\%$ \\
\hline $1500-1515$ & 4 & 28 & 10 & 72 & 0 & 0 & 0 & 0 & 0 & 0 \\
\hline Carlos I & 63 & 50 & 50 & 40 & 2 & 2 & 2 & 2 & 8 & 6 \\
\hline Felipe II & 119 & 58 & 82 & 40 & 2 & 1 & 2 & 1 & 1 & 0 \\
\hline Siglo XVI & 186 & 54 & 142 & 41 & 4 & 1 & 4 & 1 & 9 & 3 \\
\hline Felipe III & 23 & 27 & 56 & 65 & 6 & 7 & 1 & 1 & 0 & 0 \\
\hline Felipe IV & 64 & 26 & 159 & 64 & 25 & 10 & 0 & 0 & 1 & 0 \\
\hline Carlos II & 51 & 25 & 126 & 63 & 12 & 6 & 4 & 2 & 8 & 4 \\
\hline Siglo XVII & 138 & 26 & 341 & 64 & 43 & 8 & 5 & 1 & 9 & 2 \\
\hline Felipe V & 47 & 19 & 170 & 68 & 20 & 8 & 9 & 4 & 4 & 2 \\
\hline Fernando VI & 12 & 14 & 63 & 74 & 5 & 6 & 4 & 5 & 1 & 1 \\
\hline Carlos III & 24 & 12 & 155 & 79 & 15 & 8 & 1 & 0,5 & 1 & 0,5 \\
\hline 1789-1799 & 6 & 8 & 64 & 84 & 6 & 8 & 0 & 0 & 0 & 0 \\
\hline Siglo XVIII & 89 & 15 & 452 & 74 & 46 & 8 & 14 & 2 & 6 & 1 \\
\hline
\end{tabular}

Las plazas africanas, que implicaban un riesgo personal importante para los allí destinados, fueron poco apetecidas por la nobleza titulada y únicamente en Ceuta y en Orán tienen una presencia importante -un 63\% en Orán y un 48\% en Ceuta-, el resto de los cargos son ocupados por militares de carrera, y no siempre de alto rango.

55. LÁZARO ÁVILA, C., Las fronteras de América y los Flandes indianos, Madrid, CSIC, 1997. 
TABLA 41. Origen social de los gobernadores de las plazas africanas ${ }^{56}$.

\begin{tabular}{|c|c|c|c|c|c|c|c|c|c|c|}
\hline \multirow[t]{2}{*}{ Reinado } & \multicolumn{2}{|c|}{ BUROCRACIA } & \multicolumn{2}{|c|}{ MILITARES } & \multicolumn{2}{|c|}{$\begin{array}{c}\text { ALTA } \\
\text { NOBLEZA }\end{array}$} & \multicolumn{2}{|c|}{$\begin{array}{c}\text { ÉLITES } \\
\text { LOCALES }\end{array}$} & \multicolumn{2}{|c|}{ CLERO } \\
\hline & $\mathrm{N}^{\circ}$ & $\%$ & $\mathrm{~N}^{0}$ & $\%$ & $\mathrm{~N}^{\circ}$ & $\%$ & $\mathrm{~N}^{\circ}$ & $\%$ & $\mathrm{~N}^{0}$ & $\%$ \\
\hline 1500-1515 & 0 & 0 & 3 & 75 & 1 & 25 & 0 & 0 & 0 & 0 \\
\hline Carlos I & 0 & 0 & 7 & 70 & 3 & 30 & 0 & 0 & 0 & 0 \\
\hline Felipe II & 0 & 0 & 11 & 61 & 7 & 39 & 0 & 0 & 0 & 0 \\
\hline Felipe III & 0 & 0 & 5 & 62 & 3 & 38 & 0 & 0 & 0 & 0 \\
\hline Felipe IV & 0 & 0 & 23 & 59 & 16 & 41 & 0 & 0 & 0 & 0 \\
\hline Carlos II & 0 & 0 & 21 & 54 & 16 & 41 & 0 & 0 & 2 & 5 \\
\hline Felipe V & 0 & 0 & 17 & 61 & 11 & 39 & 0 & 0 & 0 & 0 \\
\hline Fernando VI & 0 & 0 & 6 & 67 & 3 & 33 & 0 & 0 & 0 & 0 \\
\hline Carlos III & 0 & 0 & 15 & 79 & 4 & 21 & 0 & 0 & 0 & 0 \\
\hline 1789-1799 & 0 & 0 & 7 & 70 & 3 & 30 & 0 & 0 & 0 & 0 \\
\hline TOTAL & $\mathbf{0}$ & $\mathbf{0}$ & 115 & 63 & 67 & 36 & $\mathbf{0}$ & $\mathbf{0}$ & 2 & 1 \\
\hline
\end{tabular}

Durante los siglos XVI y XVII, junto a los cargos de perfil más político -virreyes y gobernadores-, las posesiones europeas implicaron un despliegue militar de enorme magnitud, con varias decenas de plazas en las que había que sostener una guarnición permanente ${ }^{57}$. La mayoría de ellas eran dirigidas por militares de bajo nivel, capitanes normalmente, pero algunas de mayor importancia requerían personal de más alto rango. Desgraciadamente, poco o nada sabemos sobre la mayoría de ellas, pero con las que conocemos su cadena de mando podemos extraer algunas conclusiones. Eran puestos reservados, lógicamente, a nobles y militares experimentados, pero observamos como la nobleza titulada huía de la mayoría de estos destinos y sólo tiene una presencia mayoritaria en los más prestigiosos, como Amberes, Gante o Cambrai, y apenas superando el 50\% de los puestos además, un $10 \%$ de los gobernadores nobles eran extranjeros miembros de la aristocracia local-.

56. Gobernadores de La Goleta, Larache, Orán, La Mármora, Melilla y Ceuta (desde 1640).

57. Véase PARKER, G., El Ejército de Flandes y el Camino Español, Madrid, 1976; y THOMPSON, I. A. A., Guerra y decadencia: gobierno y administración en la España de los Austrias, 1560-1620, Barcelona, Crítica, 1981; y "Los ejércitos de Felipe II: del tercio a la milicia", en RIBOT GARCÍA L. A. y BELENGUER CEBRIÀ, E. (coord.), Las sociedades ibéricas y el mar a finales del siglo XVI, Vol. 2, 1998, pp. 477-496. 
TABLA 42. Origen social de los gobernadores de las plazas europeas ${ }^{58}$.

\begin{tabular}{|c|c|c|c|c|c|c|c|c|c|c|}
\hline \multirow{2}{*}{ Reinado } & \multicolumn{2}{|c|}{ BUROCRACIA } & \multicolumn{2}{|c|}{ MILITARES } & \multicolumn{2}{|c|}{$\begin{array}{c}\text { ALTA } \\
\text { NOBLEZA }\end{array}$} & \multicolumn{2}{|c|}{$\begin{array}{c}\text { ÉLITES } \\
\text { LOCALES }\end{array}$} & \multicolumn{2}{|c|}{ CLERO } \\
\hline & $\mathrm{N}^{\mathbf{o}}$ & $\%$ & $\mathbf{N}^{0}$ & $\%$ & $\mathbf{N}^{\circ}$ & $\%$ & $\mathbf{N}^{\circ}$ & $\%$ & $\mathbf{N}^{\circ}$ & $\%$ \\
\hline Carlos I & 0 & 0 & 7 & 58 & 5 & 42 & 0 & 0 & 0 & 0 \\
\hline Felipe II & 0 & 0 & 40 & 80 & 10 & 20 & 0 & 0 & 0 & 0 \\
\hline Felipe III & 0 & 0 & 20 & 80 & 5 & 20 & 0 & 0 & 0 & 0 \\
\hline Felipe IV & 0 & 0 & 59 & 80 & 15 & 20 & 0 & 0 & 0 & 0 \\
\hline Carlos II & 0 & 0 & 40 & 64 & 22 & 35 & 0 & 0 & 0 & 0 \\
\hline Felipe V & 0 & 0 & 8 & 61 & 5 & 38 & 0 & 0 & 0 & 0 \\
\hline
\end{tabular}

Los virreinatos eran los cargos de mayor relevancia en los territorios no castellanos de los Austrias -en el XVIII sólo subsistirán el de Navarra y los coloniales-, de modo que la presencia nobiliaria es, como cabía esperar, mayoritaria, especialmente en las posesiones más destacadas, como Cataluña, Navarra, Valencia o Nápoles, con porcentajes que se acercan o superan el $80 \%$ de las designaciones. En términos diacrónicos, es durante los reinados de Felipe IV y Carlos II cuando la presencia nobiliaria es mayor. El grupo social más beneficiado por la pérdida de peso de los nobles en el siglo XVIII fueron, desde luego, los militares, con un $70 \%$ de las designaciones durante los reinados de Fernando VI y Carlos III.

TABLA 43. Origen social de los virreyes ${ }^{59}$.

\begin{tabular}{|c|c|c|c|c|c|c|c|c|c|c|}
\hline \multirow{2}{*}{ Reinado } & \multicolumn{2}{|c|}{ BUROCRACIA } & \multicolumn{2}{|c|}{ MILITARES } & \multicolumn{2}{|c|}{$\begin{array}{c}\text { ALTA } \\
\text { NOBLEZA }\end{array}$} & \multicolumn{2}{|c|}{$\begin{array}{c}\text { ÉLITES } \\
\text { LOCALES }\end{array}$} & \multicolumn{2}{|c|}{ CLERO } \\
\hline & $\mathbf{N}^{\mathbf{o}}$ & $\%$ & $\mathrm{~N}^{\mathbf{o}}$ & $\%$ & $\mathrm{~N}^{0}$ & $\%$ & $N^{o}$ & $\%$ & $\mathbf{N}^{0}$ & $\%$ \\
\hline $1500-1515$ & 3 & 16 & 2 & 10 & 8 & 42 & 0 & 0 & 6 & 31 \\
\hline Carlos I & 7 & 12 & 7 & 12 & 36 & 62 & 0 & 0 & 8 & 14 \\
\hline Felipe II & 6 & 5 & 10 & 9 & 76 & 67 & 0 & 0 & 12 & 10 \\
\hline
\end{tabular}

58. Gobernadores y Alcaides de las fortalezas de Cambrai, Amberes, Gante, Ostende, Niewport, Alessandría, Milán, Cremona, Finale, Nápoles, San Salvatore de Mesina y Orbetello.

59. Véase: MONTORO LÓPEZ, J., Los virreyes españoles en América, Barcelona, Mitre, 1991, RIVERO RODRíGUEZ, M., La edad de oro de los virreyes. El virreinato en la Monarquía Hispánica durante los siglos XVI y XVII, Madrid, Akal, 2011, HERNANDO SÁNCHEZ, C. J., "Los virreyes de la monarquía española en Italia. Evolución y práctica de un oficio de gobierno", Studia historica. Historia Moderna, no 26, 2004, pp. 43-73. 


\begin{tabular}{|l|c|c|c|c|c|c|c|c|c|c|}
\hline \multirow{2}{*}{ Reinado } & \multicolumn{2}{|c|}{ BUROCRACIA } & \multicolumn{2}{c|}{ MILITARES } & \multicolumn{2}{c|}{$\begin{array}{c}\text { ALTA } \\
\text { NOBLEZA }\end{array}$} & \multicolumn{2}{c|}{$\begin{array}{c}\text { ÉLITES } \\
\text { LOCALES }\end{array}$} & \multicolumn{2}{c|}{ CLERO } \\
\cline { 2 - 13 } & $\mathbf{N}^{\mathbf{0}}$ & $\mathbf{\%}$ & $\mathbf{N}^{\mathbf{0}}$ & $\mathbf{\%}$ & $\mathbf{N}^{\mathbf{0}}$ & $\mathbf{\%}$ & $\mathbf{N}^{\mathbf{0}}$ & $\mathbf{\%}$ & $\mathbf{N}^{\mathbf{0}}$ & $\mathbf{\%}$ \\
\hline Siglo XVI & $\mathbf{1 6}$ & $\mathbf{9}$ & $\mathbf{1 9}$ & $\mathbf{1 0}$ & $\mathbf{1 2 0}$ & $\mathbf{6 6}$ & $\mathbf{0}$ & $\mathbf{0}$ & $\mathbf{2 6}$ & $\mathbf{1 4}$ \\
\hline Felipe III & 0 & 0 & 4 & 7 & 37 & 64 & 0 & 0 & 17 & 29 \\
\hline Felipe IV & 5 & 3 & 10 & 6 & 112 & 72 & 0 & 0 & 28 & 18 \\
\hline Carlos II & 3 & 3 & 3 & 3 & 80 & 84 & 0 & 0 & 9 & 9 \\
\hline Siglo XVII & $\mathbf{8}$ & $\mathbf{3}$ & $\mathbf{1 7}$ & $\mathbf{6}$ & $\mathbf{2 2 9}$ & $\mathbf{7 4}$ & $\mathbf{0}$ & $\mathbf{0}$ & $\mathbf{5 4}$ & $\mathbf{1 7}$ \\
\hline Felipe V & 3 & 7 & 9 & 20 & 25 & 57 & 0 & 0 & 7 & 16 \\
\hline Fernando VI & 0 & 0 & 5 & 71 & 1 & 14 & 0 & 0 & 1 & 14 \\
\hline Carlos III & 0 & 0 & 19 & 70 & 7 & 26 & 0 & 0 & 1 & 4 \\
\hline 1789-1799 & 3 & 20 & 6 & 40 & 6 & 40 & 0 & 0 & 0 & 0 \\
\hline Siglo XVIII & $\mathbf{6}$ & $\mathbf{6}$ & $\mathbf{3 9}$ & $\mathbf{4 2}$ & $\mathbf{3 9}$ & $\mathbf{4 2}$ & $\mathbf{0}$ & $\mathbf{0}$ & $\mathbf{9}$ & $\mathbf{1 0}$ \\
\hline
\end{tabular}

Los estados de Flandes y Milán, al no tener rango de reinos, no eran regidos por un virrey, sino por un Gobernador, aunque con similares atribuciones. Su extracción social es similar a la de los virreinatos más prestigiosos, especialmente Flandes, donde incluso 11 miembros de la propia Casa Real Ilegaron a ser designados gobernadores.

TABLA 44. Gobernadores de Flandes y Milán.

\begin{tabular}{|l|c|c|c|c|c|c|}
\hline \multirow{2}{*}{ Reinado } & \multicolumn{2}{|c|}{ MILITARES } & \multicolumn{2}{c|}{ NOBLES } & \multicolumn{2}{c|}{ CLERO } \\
\cline { 2 - 7 } & $\mathbf{N}^{\mathbf{0}}$ & $\mathbf{\%}$ & $\mathbf{N}^{\mathbf{0}}$ & $\mathbf{\%}$ & $\mathbf{N}^{\mathbf{0}}$ & $\mathbf{\%}$ \\
\hline $1500-1515$ & 0 & 0 & 1 & 100 & 0 & 0 \\
\hline Carlos I & 1 & 11 & 7 & 78 & 1 & 11 \\
\hline Felipe II & 5 & 20 & 18 & 72 & 2 & 8 \\
\hline Felipe III & 1 & 13 & 7 & 87 & 0 & 0 \\
\hline Felipe IV & 0 & 0 & 24 & 89 & 3 & 11 \\
\hline Carlos II & 0 & 0 & 16 & 100 & 0 & 0 \\
\hline Felipe V & 0 & 0 & 2 & 100 & 0 & 0 \\
\hline
\end{tabular}

En el siglo XVIII desaparecen los virreinatos y los de la Corona de Aragón son sustituidos por capitanías generales, institución que también se implantó en el resto de las regiones españolas. En los viejos virreinatos aragoneses, la presencia de nobles titulados superó en los siglos XVI y XVII el 80\% de las designaciones, 
mientras que en el XVIII en ninguna Capitanía General se alcanzó el 70\% siendo ese espacio ocupado por militares de carrera.

TABLA 45. La alta nobleza en las capitanías generales del siglo XVIII61.

\begin{tabular}{|l|c|c|c|}
\hline \multicolumn{1}{|c|}{ CAPITANÍA } & $\begin{array}{c}\text { NÚMERO } \\
\text { C.G. }\end{array}$ & $\begin{array}{c}\text { NOBLES } \\
\text { TITULADOS }\end{array}$ & \% TITULADOS \\
\hline Cataluña & 32 & 22 & 69 \\
\hline Valencia & 19 & 13 & 68 \\
\hline Extremadura & 14 & 9 & 64 \\
\hline Andalucía & 12 & 6 & 50 \\
\hline Canarias & 21 & 5 & 24 \\
\hline Aragón & 19 & 13 & 68 \\
\hline Mallorca & 28 & 9 & 24 \\
\hline Galicia & 17 & 10 & 59 \\
\hline TOTAL & $\mathbf{1 6 2}$ & $\mathbf{8 7}$ & $\mathbf{5 4}$ \\
\hline
\end{tabular}

Un escalón más abajo, en los gobiernos militares de la Península, observamos que durante los siglos XVI y XVII, salvo en Galicia y en Canarias, cuyos titulares tenían también el rango de Capitán General, la presencia de nobles es relativamente escasa. Las nuevas gobernaciones creadas durante el siglo XVIII, mejor retribuidas y ubicadas, sobre todo en la Corona de Aragón, en plazas importantes, fueron más atractivas para los nobles de lo que lo habían sido durante los siglos XVI y XVII, pero aun así el grupo social hegemónico fueron siempre los militares de carrera.

60. Incluyo en estos cálculos a los capitanes generales interinos, dado que a menudo ocuparon el cargo durante periodos de tiempo significativamente largos.

61. Los datos de las Capitanías de Extremadura y Andalucía proceden de ANDÚJAR CASTILLO, F., "Capitanes generales y capitanías generales en el siglo XVIII", Revista de Historia Moderna. Anales de la Universidad de Alicante, $\mathrm{n}^{\circ} 22,2004$, p. 21. La información sobre los capitanes generales de Aragón, Galicia, Cataluña, Valencia, Canarias y Mallorca está elaborada por mi a partir de BOVER, J. M., Noticias histórico-topográficas de Mallorca, Palma de Mallorca, 1836 y La Capitanía General de Aragón. 1711-2011, Zaragoza, Ministerio de Defensa, 2012. Datos globales en OZANAM, D., Capitanes y Comandantes Generales de Provincias en la España del siglo XVIII: estudio preliminar y repertorio biográfico, Córdoba, Universidad de Córdoba, 2008. 
TABLA 46. Origen social de los gobernadores militares peninsulares ${ }^{62}$.

\begin{tabular}{|c|c|c|c|c|c|c|c|c|c|c|}
\hline \multirow[t]{2}{*}{ Reinado } & \multicolumn{2}{|c|}{ BUROCRACIA } & \multicolumn{2}{|c|}{ MILITARES } & \multicolumn{2}{|c|}{$\begin{array}{c}\text { ALTA } \\
\text { NOBLEZA }\end{array}$} & \multicolumn{2}{|c|}{$\begin{array}{c}\text { ÉLITES } \\
\text { LOCALES }\end{array}$} & \multicolumn{2}{|c|}{ CLERO } \\
\hline & $\mathbf{N}^{\circ}$ & $\%$ & $\mathbf{N}^{o}$ & $\%$ & $\mathrm{~N}^{\mathbf{o}}$ & $\%$ & $\mathrm{~N}^{\mathbf{0}}$ & $\%$ & $\mathbf{N}^{\mathbf{o}}$ & $\%$ \\
\hline $1500-1515$ & 1 & 33 & 1 & 33 & 0 & 0 & 0 & 0 & 1 & 33 \\
\hline Carlos I & 2 & 17 & 6 & 50 & 4 & 33 & 0 & 0 & 0 & 0 \\
\hline Felipe II & 7 & 30 & 12 & 52 & 4 & 18 & 0 & 0 & 0 & 0 \\
\hline Siglo XVI & 10 & 26 & 19 & 50 & 8 & 21 & $\mathbf{0}$ & $\mathbf{0}$ & 1 & 3 \\
\hline Felipe III & 0 & 0 & 7 & 64 & 4 & 36 & 0 & 0 & 0 & 0 \\
\hline Felipe IV & 0 & 0 & 43 & 67 & 18 & 28 & 0 & 0 & 3 & 5 \\
\hline Carlos II & 1 & 2 & 28 & 55 & 21 & 41 & 0 & 0 & 1 & 2 \\
\hline Siglo XVII & 1 & 1 & 78 & 62 & 43 & 35 & $\mathbf{0}$ & $\mathbf{0}$ & 4 & 3 \\
\hline Felipe V & 4 & 3 & 73 & 56 & 52 & 41 & 0 & 0 & 0 & 0 \\
\hline Fernando VI & 0 & 0 & 22 & 76 & 7 & 24 & 0 & 0 & 0 & 0 \\
\hline Carlos III & 2 & 2 & 55 & 55 & 42 & 42 & 0 & 0 & 0 & 0 \\
\hline 1789-1799 & 2 & 3 & 54 & 67 & 24 & 30 & 0 & 0 & 0 & 0 \\
\hline Siglo XVIII & 8 & 2 & 254 & 66 & 125 & 32 & $\mathbf{0}$ & 0 & 0 & $\mathbf{0}$ \\
\hline TOTAL & 19 & 4 & 301 & 60 & 176 & 35 & 0 & 0 & 5 & 1 \\
\hline
\end{tabular}

Un peldaño más abajo en el escalafón burocrático encontramos a los corregidores y, ya en el siglo XVIII, a los intendentes. Los corregimientos no eran, salvo excepciones, cargos bien pagados -especialmente en los siglos XVI y XVII-y tampoco de gran prestigio social, de ahí que la presencia de nobles titulados ocupando estos oficios sea más que discreta, pues según la estimación global hecha por Ignacio Fortea sólo supusieron un 3\% de total de 1.012 designaciones hechas entre 1588 y $1633^{63}$.

Sin embargo, determinados corregimientos, mejor remunerados $y$, sobre todo, políticamente más relevantes, sí que fueron apetecidos por la aristocracia, de manera que nos sirven también para evaluar el peso político de cada grupo social. Diacrónicamente, la mayor presencia de la alta nobleza se produce,

62. Se incluyen las Capitanías Generales de Canarias, Galicia, Aragón, Valencia, Cataluña y Mallorca, y los Gobiernos Militares de Fuenterravía, Jaca, Badajoz, Alicante, Castellón, Cádiz, Puerto de Santa María, Gibraltar, Almería, Sanlúcar, Málaga, Lérida, Gerona, Barcelona y Tarragona.

63. La tabla está elaborada a partir de los datos recogidos por FORTEA, I., en "Los corregidores de Castilla bajo los Austrias: Elementos para el estudio prosopográfico de un grupo de poder (1588-1633)", Studia historica. Historia Moderna, n 34, 2012, pp. 97-144. 
como casi siempre, en el reinado de Carlos II -el 50\% del reinado de Carlos IV se basa en una muestra muy pequeña, de seis nombramientos- . Los burócratas alcanzan las mayores cotas de poder durante el siglo XVI y durante la segunda mitad del siglo XVIII.

TABla 47. Origen social de los corregidores ${ }^{64}$. Por reinado (Madrid, Sevilla asistentes-, Granada, Toledo, Jerez).

\begin{tabular}{|c|c|c|c|c|c|c|c|c|}
\hline \multirow{2}{*}{ Reinado } & \multicolumn{2}{|c|}{ BUROCRACIA } & \multicolumn{2}{|c|}{ MILITARES } & \multicolumn{2}{|c|}{$\begin{array}{c}\text { ALTA } \\
\text { NOBLEZA }\end{array}$} & \multicolumn{2}{|c|}{ CLERO } \\
\hline & $\mathbf{N}^{\mathbf{0}}$ & $\%$ & $\mathrm{~N}^{\mathbf{o}}$ & $\%$ & $\mathrm{~N}^{\mathrm{o}}$ & $\%$ & $\mathbf{N}^{\mathbf{o}}$ & $\%$ \\
\hline 1500-1515 & 11 & 68 & 2 & 12 & 3 & 18 & 0 & 0 \\
\hline Carlos I & 31 & 48 & 23 & 35 & 9 & 14 & 1 & 1 \\
\hline Felipe II & 49 & 69 & 5 & 7 & 17 & 23 & 0 & 0 \\
\hline Siglo XVI & 91 & 61 & 30 & 20 & 29 & 19 & 1 & $\mathbf{0}$ \\
\hline Felipe III & 9 & 39 & 6 & 26 & 8 & 34 & 0 & 0 \\
\hline Felipe IV & 28 & 43 & 8 & 12 & 29 & 44 & 0 & 0 \\
\hline Carlos II & 25 & 46 & 2 & 3 & 27 & 50 & 0 & 0 \\
\hline Siglo XVII & 62 & 44 & 16 & 11 & 64 & 45 & $\mathbf{0}$ & $\mathbf{0}$ \\
\hline Felipe V & 20 & 39 & 12 & 23 & 19 & 37 & 0 & 0 \\
\hline Fernando VI & 6 & 60 & 0 & 0 & 4 & 40 & 0 & 0 \\
\hline Carlos III & 24 & 92 & 1 & 4 & 1 & 4 & 0 & 0 \\
\hline Carlos IV & 3 & 50 & 0 & 0 & 3 & 50 & 0 & 0 \\
\hline Siglo XVIII & 53 & 57 & 13 & 14 & 27 & 29 & $\mathbf{0}$ & $\mathbf{0}$ \\
\hline TOTAL & 206 & 53 & 59 & 15 & 120 & 31 & 1 & $\mathbf{0}$ \\
\hline
\end{tabular}

64. El corregimiento de Madrid sólo fue relevante, en realidad, a partir de la instalación de la Corte, pero he respetado la serie completa desde 1500. En cualquier caso, 16 de los 19 nobles titulados que ocuparon este corregimiento fueron nombrados por Felipe IV y Carlos II. La información sobre estos corregimientos procede, mayoritariamente, de HERNÁNDEZ, M., "La evolución de un delegado regio: corregidores de Madrid en los siglos XVII y XVIII", Anuario de historia del derecho español, no 61, 1991, pp. 579 y ss.; ARANA, F., Compendio histórico descriptivo de la muy noble y muy leal ciudad de Sevilla, metrópoli de Andalucía, Sevilla, 1789, pp. 25 y ss.; DÍAZ-MARTÍN DE CABRERA, J., Curiosidades históricas granadinas: segunda parte: los muy ilustres Señores Corregidores de la Ciudad de Granada, Granada, 1919; y ARANDA PÉREZ, F. J., “Nobles, discretos varones que gobernáis a Toledo. Una guía prosopográfica de los componentes del poder municipal en Toledo durante la Edad Moderna (corregidores, dignidades y regidores)", en Poderes intermedios, poderes interpuestos. Sociedad y oligarquías en la España Moderna, Cuenca, Universidad de Castilla-La Mancha, 1999, pp. 235-240. 
Los intendentes del siglo XVIII eran funcionarios mejor remunerados y con mucho más poder que los corregidores de los Austrias, de ahí que fuesen puestos muy apetecidos, quizá no por los linajes nobiliarios de más rancio abolengo, pero si por la nueva alta nobleza surgida a partir del siglo XVII. Del cuadro siguiente se desprende que estos cargos, aunque siempre tuvieron presencia de nobles y de militares, se burocratizaron y se profesionalizaron cada vez más a lo largo del siglo.

TABLA 48. Origen social de los intendentes por reinado ${ }^{65}$.

\begin{tabular}{|c|c|c|c|c|c|c|c|c|c|c|}
\hline \multirow[t]{2}{*}{ Reinado } & \multicolumn{2}{|c|}{ BUROCRACIA } & \multicolumn{2}{|c|}{ MILITARES } & \multicolumn{2}{|c|}{$\begin{array}{c}\text { ALTA } \\
\text { NOBLEZA }\end{array}$} & \multicolumn{2}{|c|}{$\begin{array}{c}\text { ÉLITES } \\
\text { LOCALES }\end{array}$} & \multicolumn{2}{|c|}{ CLERO } \\
\hline & $\mathbf{N}^{0}$ & $\%$ & $\mathbf{N}^{\mathbf{o}}$ & $\%$ & $N^{o}$ & $\%$ & $\mathbf{N}^{\circ}$ & $\%$ & $\mathrm{~N}^{\mathbf{o}}$ & $\%$ \\
\hline Felipe V & 24 & 53 & 9 & 20 & 12 & 27 & 0 & 0 & 0 & 0 \\
\hline Fernando VI & 21 & 54 & 7 & 18 & 11 & 28 & 0 & 0 & 0 & 0 \\
\hline Carlos III & 63 & 71 & 11 & 12 & 14 & 16 & 0 & 0 & 0 & 0 \\
\hline 1789-1799 & 35 & 73 & 5 & 10 & 8 & 17 & 0 & 0 & 0 & 0 \\
\hline TOTAL & 143 & 65 & 32 & 14 & 45 & 20 & $\mathbf{0}$ & $\mathbf{0}$ & $\mathbf{0}$ & $\mathbf{0}$ \\
\hline
\end{tabular}

Durante el siglo XVIII, la evolución de los corregimientos parece haber sido diferente según regiones, mientras que en Aragón y Cataluña el predominio de los letrados en estos cargos parece haber ido creciendo con el tiempo, en el País Valenciano sucedió lo contrario. Para la Corona de Castilla, peor conocida, tenemos información detallada sobre Andalucía, donde se detecta un creciente peso de los corregidores letrados ${ }^{66}$.

Un elemento extraño, capaz algunas veces de socavar las relaciones de poder en la Corte, por lo que siempre preocupó y mucho a los nobles españoles, y no sólo a ellos, también a la población en general, fue la presencia de ex-

65. Se incluyen las Intendencias de Burgos, Cataluña, Aragón, Murcia, Salamanca, MaIlorca, La Mancha, Valencia, Ávila, Córdoba, Cuenca, Jaén, León, Granada, Guadalajara y Andalucía. La información sobre los intendentes procede, en su mayoría, de ABBAD, F. y OZANAM, D., Les intendants espagnols du XVIIIle siècle, Madrid, 1992.

66. Los datos proceden de ÁLVAREZ CAÑAS, M. L., Corregidores y alcaldes mayores: la administración territorial andaluza en el siglo XVIII, Alicante, 2012, p. 378. Para los corregimientos de la Corona de Aragón véase GARCÍA MONERRIS, E., La monarquía absoluta y el municipio borbónico: la reorganización de la oligarquía urbana del Ayuntamiento de Valencia, Madrid, 1991, pp. 43-48; GIMÉNEZ LÓPEZ, E., "La Nueva Planta de Aragón: corregimientos y corregidores en el reinado de Felipe V", Argensola: Revista de Ciencias Sociales del Instituto de Estudios Altoaragoneses, $\mathrm{n}^{\circ}$ 101, 1988, pp. 9-50; y "Los corregidores de Alicante: perfil sociológico y político de una élite militar", Revista de historia moderna: Anales de la Universidad de Alicante, $\mathrm{n}^{\circ}$ 6-7, 1986-87, pp. 67-86; y TORRAS I RIBÉ, J. M., Els municipis catalans de l'Antic Règim, Barcelona, Curial, 1983. 
tranjeros ocupando cargos públicos en España. Las leyes castellanas, navarras y catalano-aragonesas lo prohibían expresamente, pero en la práctica siempre existía el riesgo de su presencia dado el carácter internacional de las posesiones del rey de España durante la época de los Austrias y la posibilidad que tenía el rey de naturalizar vía decreto a quien desease. La mala experiencia sufrida por Carlos I tras llegar al trono de Castilla puede que sirviera de advertencia a sus sucesores, pero lo cierto es que el fenómeno de la presencia de extranjeros fue relativamente escaso y limitado a la Corona de Aragón y Navarra, donde la media es de un $14 \%$ de extranjeros entre sus virreyes durante los siglos XVI y XVII ${ }^{67}$.

Lo que realmente ocurrió fue el fenómeno contrario, es decir, la presencia masiva de españoles, especialmente castellanos, en los puestos de mando civiles y sobre todo militares de todas las posesiones europeas: tan sólo el virreinato de Portugal -con un $80 \%$ de portugueses ${ }^{68}$ - y la Gobernación de Flandes -con un $50 \%$ de no españoles- escapan a esta regla entre los ámbitos de poder que hemos contabilizado.

TABLA 49. Extranjeros en los altos mandos del ejército y en el gobierno de algunas posesiones europeas de los Austrias.

\begin{tabular}{|c|c|c|c|c|}
\hline \multirow{2}{*}{ CARGOS } & \multicolumn{2}{|c|}{ ESPAÑOLES } & \multicolumn{2}{|c|}{ EXTRANJEROS } \\
\hline & $\mathbf{N}^{\mathbf{o}}$ & $\%$ & $N^{0}$ & $\%$ \\
\hline Gobiernos militares en Flandes ${ }^{1}$ & 88 & 90 & 9 & 10 \\
\hline Gobiernos militares en Italia ${ }^{2}$ & 124 & 96 & 4 & 4 \\
\hline Altos mandos Ejército de Flandes ${ }^{3}$ & 59 & 53 & 52 & 47 \\
\hline Altos mandos Ejército de Italia ${ }^{4}$ & 46 & 75 & 15 & 25 \\
\hline Altos mandos Ejército de Portugal ${ }^{5}$ & 7 & 70 & 3 & 30 \\
\hline Gobernadores de Flandes & 14 & 50 & 14 & 50 \\
\hline Gobernadores de Milán & 46 & 82 & 10 & 18 \\
\hline Virreyes de Cerdeña & 65 & 86 & 10 & 14 \\
\hline Virreyes de Sicilia & 60 & 65 & 32 & 35 \\
\hline Virreyes de Nápoles & 48 & 90 & 5 & 10 \\
\hline Virreyes de Portugal & 3 & 17 & 14 & 83 \\
\hline
\end{tabular}

67. A sus ojos, el porcentaje de "extranjeros" era mucho mayor, pues los castellanos también eran considerados como tales.

68. La confianza en la fidelidad de los portugueses fue siempre escasa, no en vano los 5 maestres de campo que mandaron el Tercio de Lisboa, el único acuartelado en el reino, fueron todos españoles, y también fueron españoles 7 de los 10 Maestres de Campo Generales del Ejército de Portugal -los otros tres, dos flamencos y un italiano-. 


\begin{tabular}{|l|c|c|c|c|}
\hline \multirow{2}{*}{\multicolumn{1}{|c|}{ CARGOS }} & \multicolumn{2}{c|}{ ESPAÑLES } & \multicolumn{2}{c|}{ EXTRANJEROS } \\
\cline { 2 - 5 } & $\mathbf{N}^{\mathbf{0}}$ & $\mathbf{\%}$ & $\mathbf{N}^{\mathbf{0}}$ & $\mathbf{\%}$ \\
\hline Virreyes de Aragón & 28 & 80 & 7 & 20 \\
\hline Virreyes de Cataluña & 54 & 84 & 10 & 16 \\
\hline Virreyes de Navarra & 53 & 85 & 9 & 15 \\
\hline Virreyes de Valencia & 44 & 89 & 5 & 11 \\
\hline Virreyes de Mallorca & 34 & 94 & 2 & 6 \\
\hline TOTAL & $\mathbf{7 7 4}$ & $\mathbf{7 9}$ & $\mathbf{2 0 0}$ & $\mathbf{2 1}$ \\
\hline
\end{tabular}

1 Se incluyen las de Amberes, Cambrai, Gante, Ostende y Nieuwport.

2. Se incluyen las de San Telmo, Alessandría, Castillo de Milán, Cremona, San Salvatore, Orbetello y Finale.

3 Se incluyen los Maestres Generales (no los de los Tercios), Capitanes Generales de la Caballería, Capitanes Generales de la Artillería y Tenientes Generales de la Caballería.

4 Se incluyen los Capitanes Generales de la Caballería y de la Artillería.

5 Se incluyen los Maestres de Campo Generales del Ejército de Portugal.

Curiosamente, es en el siglo XVIII, pese a que ya no se poseen territorios en Europa, cuando mayor es la presencia de extranjeros ocupando cargos de gobierno en España. Las capitanías generales, los puestos de mayor relieve, tuvieron una presencia de extranjeros superior a la que observábamos en la época de los Austrias, especialmente durante el reinado de Felipe V.

TABLA 50. Capitanes generales extranjeros (1700-1808) ${ }^{69}$.

\begin{tabular}{|l|c|c|c|c|c|}
\hline \multicolumn{1}{|c|}{ Reinado } & CATALUÑA & GALICIA & MALLORCA & VALENCIA & TOTAL \\
\hline Felipe V & $10(67 \%)$ & $6(46 \%)$ & $3(50 \%)$ & $7(41 \%)$ & $26(51 \%)$ \\
\hline Fernando VI & - & $1(8 \%)$ & $1(17 \%)$ & - & $2(4 \%)$ \\
\hline Carlos III & $3(20 \%)$ & $3(23 \%)$ & $2(33 \%)$ & $6(35 \%)$ & $14(27 \%)$ \\
\hline Carlos IV & $2(13 \%)$ & $3(23 \%)$ & - & $4(23 \%)$ & $9(18 \%)$ \\
\hline
\end{tabular}

En los Virreinatos que perduran durante el siglo XVIII -los coloniales y Navarra-, la presencia de extranjeros es inferior al que se detecta en las Capitanías Generales, aunque es significativa en Navarra y Perú, con un 25\%, porcentajes

69. Datos tomados de CAIMARI CALAFAT, T., "Los extranjeros en la alta administración española del siglo XVIII: el caso de los capitanes generales de Mallorca", en VILLAR GARCÍA, M. B. (dir.), Los extranjeros en la España moderna, Vol. 2, 2003, pp. 149-160. 
muy superiores a los de los siglos XVI y XVII, cuando los extranjeros en Navarra supusieron el 15\% y en Perú y Nueva España el 0\%.

TABLA 51. Extranjeros en los virreinatos (s. XVIII).

\begin{tabular}{|l|c|c|c|}
\hline \multirow{2}{*}{ Virreinato } & \multirow{2}{*}{ TOTAL VIRREYES } & \multicolumn{2}{c|}{ VIRREYES EXTRANJEROS } \\
\cline { 3 - 4 } & & $\mathbf{N}^{\mathbf{o}}$ & $\mathbf{\%}$ \\
\hline Nueva España & 23 & 1 & 4 \\
\hline Perú & 16 & 4 & 25 \\
\hline Navarra & 24 & 6 & 25 \\
\hline Nueva Granada & 14 & 0 & 0 \\
\hline Río de la Plata & 7 & 0 & 0 \\
\hline TOTAL & $\mathbf{8 4}$ & $\mathbf{1 1}$ & $\mathbf{1 3}$ \\
\hline
\end{tabular}

Entre los altos oficiales del ejército de los Austrias -y a falta de un estudio prosopográfico de amplio alcance- a partir de una muestra de 569 maestres de campo que hemos podido documentar, aparecen un total de 214 extranjeros, un $37 \%$, pero en su mayoría al mando de los tercios de infantería extranjera acuartelados en Flandes e Italia. En los de infantería española los maestres extranjeros se reducen hasta el $11 \%$.

Para el siglo XVIII lo cierto es que las estimaciones publicadas no son coincidentes: Andújar Castillo habla de un 10\% de extranjeros entre los mandos y un $6 \%$ entre los oficiales -con tendencia de éstos a disminuir, pues suponían el $15 \%$ entre $1715-1735$ y cayeron hasta el $2 \%$ entre $1786-1800-$, pero Luis Balduque eleva hasta el $12 \%$ el porcentaje de oficiales extranjeros en $1776^{70}$. Sean unas cifras u otras, lo cierto es que el aumento de la presencia de extranjeros frente a la época de los Austrias que se detecta en las capitanías generales no parece mantenerse en el ejército regular.

En cuanto al acceso de extranjeros a títulos nobiliarios españoles, éste fue un fenómeno muy restringido -un 6,6\% de los títulos concedidos-y en muchos de los casos mediando matrimonios previos con hijas de nobles titulados españoles -es decir, que ya estaban asentados en España-. Fuera de esta vía, la mayoría son militares irlandeses, franceses e italianos recompensados por sus servicios en el Ejército o la Armada, siendo ya muchos de ellos previamente nobles en sus países de origen.

70. BALDUQUE, L. M., El Ejército de Carlos III: extracción social, origen geográfico y formas de vida de los Oficiales de S.M., Madrid, Tesis Doctoral, 1993. ANDÚJAR CASTILLO, F., El ejército estamental en la España del siglo XVIII, Madrid, Tesis Doctoral, 1991. 
TABLA 52. Concesión de títulos nobiliarios españoles a extranjeros e hijos de extranjeros.

\begin{tabular}{|c|c|c|c|}
\hline \multirow{2}{*}{ Reinado } & \multirow{2}{*}{ TOTAL TÍTULOS } & \multicolumn{2}{|c|}{ TÍTULOS A EXTRANJEROS } \\
\hline & & $\mathbf{N}^{\mathbf{0}}$ & $\%$ \\
\hline Carlos I & 50 & 5 & 10 \\
\hline Felipe II & 64 & 6 & 9 \\
\hline Felipe III & 114 & 10 & 9 \\
\hline Felipe IV & 268 & 28 & 10 \\
\hline Carlos II & 363 & 19 & 5 \\
\hline Felipe V & 301 & 9 & 3 \\
\hline Fernando VI & 57 & 1 & 2 \\
\hline Carlos III & 224 & 18 & 8 \\
\hline 1789-1799 & 96 & 6 & 6 \\
\hline TOTAL & 1.537 & 102 & 7 \\
\hline
\end{tabular}

\section{Cuadros comparativos finales}

TABLA 53. Presencia media de la alta nobleza en los centros de poder.

Resumen final (presencia en $\%)^{71}$.

\begin{tabular}{|c|c|c|c|c|c|c|c|c|}
\hline Periodo & Clero & Ejército & $\begin{array}{c}\text { Alta } \\
\text { Burocracia }\end{array}$ & $\begin{array}{c}\text { Gobiernos } \\
\text { provinciales }\end{array}$ & $\begin{array}{c}\text { Corregidores } \\
\text { Intendentes }\end{array}$ & $\begin{array}{c}\text { Emba- } \\
\text { jadores }\end{array}$ & Virreyes & Media \\
\hline $1500-1515$ & 59 & - & 4 & 17 & 18 & 12 & 42 & $\mathbf{2 5}$ \\
\hline $1516-1555$ & 59 & 20 & 10 & 34 & 14 & 43 & 62 & $\mathbf{3 4}$ \\
\hline $1556-1598$ & 42 & 29 & 8 & 29 & 23 & 29 & 67 & $\mathbf{3 2}$ \\
\hline $1599-1620$ & 46 & 40 & 23 & 33 & 34 & 82 & 64 & $\mathbf{4 5}$ \\
\hline $1621-1665$ & 32 & 46 & 24 & 34 & 34 & 69 & 72 & $\mathbf{4 4}$ \\
\hline $1666-1700$ & 21 & 50 & 24 & 41 & 50 & 68 & 84 & $\mathbf{4 8}$ \\
\hline $1701-1745$ & 15 & 33 & 21 & 36 & 32 & 51 & 57 & $\mathbf{3 5}$ \\
\hline $1746-1759$ & 14 & 36 & 26 & 19 & 34 & 54 & 14 & $\mathbf{2 8}$ \\
\hline $1760-1788$ & 3 & 19 & 24 & 24 & 10 & 43 & 26 & $\mathbf{2 1}$ \\
\hline $1789-1799$ & 24 & 20 & 12 & 27 & 33 & 23 & 40 & $\mathbf{2 5}$ \\
\hline MEDIA & $\mathbf{3 1}$ & $\mathbf{3 2}$ & $\mathbf{1 8}$ & $\mathbf{2 8}$ & $\mathbf{2 8}$ & $\mathbf{4 8}$ & $\mathbf{5 3}$ & \\
\hline
\end{tabular}

71. CLERO: Arzobispos y obispos; EJÉRCITO: Altos mandos de la marina borbónica, diversos jefes del ejército de Flandes e Italia y los capitanes generales de las galeras de España; ALTA BUROCRACIA: Presidentes de los Consejos y Chancillerías y Secretarios de Estado borbónicos; GOBIERNOS PROVINCIALES: Se computan las de América, Asia, África, posesiones en Flandes e Italia, las Capitanías Generales y diversas Gobernaciones; CORREGIDORES: se computan los de Madrid, Granada, Sevilla, Toledo y Jerez y los intendentes de diversas provincias. 
Tabla 54. Presencia media de los burócratas en los centros de poder. Resumen final (presencia en \%. Se excluyen los cargos militares y eclesiásticos).

\begin{tabular}{|c|c|c|c|c|c|c|}
\hline Periodo & $\begin{array}{c}\text { Alta } \\
\text { Burocracia }\end{array}$ & $\begin{array}{c}\text { Gobiernos } \\
\text { provinciales }\end{array}$ & $\begin{array}{c}\text { Corregidores } \\
\text { Intendentes }\end{array}$ & Embajadores & Virreyes & Media \\
\hline $1500-1515$ & 9 & 15 & 68 & 62 & 16 & $\mathbf{3 4}$ \\
\hline $1516-1555$ & 17 & 17 & 48 & 33 & 12 & $\mathbf{2 5}$ \\
\hline $1556-1598$ & 42 & 21 & 69 & 35 & 5 & $\mathbf{3 4}$ \\
\hline $1599-1620$ & 22 & 6 & 39 & 9 & 0 & $\mathbf{1 5}$ \\
\hline $1621-1665$ & 29 & 6 & 43 & 14 & 3 & $\mathbf{1 9}$ \\
\hline $1666-1700$ & 48 & 9 & 46 & 12 & 3 & $\mathbf{2 4}$ \\
\hline $1701-1745$ & 54 & 5 & 46 & 24 & 7 & $\mathbf{2 7}$ \\
\hline $1746-1759$ & 38 & 3 & 57 & 29 & 0 & $\mathbf{2 5}$ \\
\hline $1760-1788$ & 58 & 3 & 81 & 42 & 0 & $\mathbf{3 7}$ \\
\hline $1789-1799$ & 58 & 3 & 61 & 66 & 20 & $\mathbf{4 2}$ \\
\hline MEDIA & $\mathbf{3 7}$ & $\mathbf{8}$ & $\mathbf{5 6}$ & $\mathbf{3 3}$ & $\mathbf{7}$ & \\
\hline
\end{tabular}

Tabla 55. Presencia media de los militares en los centros de poder. Resumen final (presencia en \%. Se excluyen los cargos militares y eclesiásticos).

\begin{tabular}{|c|c|c|c|c|c|c|}
\hline Periodo & $\begin{array}{c}\text { Alta } \\
\text { Burocracia }\end{array}$ & $\begin{array}{c}\text { Gobiernos } \\
\text { provinciales }\end{array}$ & $\begin{array}{c}\text { Corregidores } \\
\text { Intendentes }\end{array}$ & Embajadores & Virreyes & Media \\
\hline $1500-1515$ & 1 & 60 & 12 & 0 & 10 & $\mathbf{1 7}$ \\
\hline $1516-1555$ & 0 & 55 & 35 & 6 & 12 & $\mathbf{2 2}$ \\
\hline $1556-1598$ & 0 & 59 & 7 & 12 & 9 & $\mathbf{1 7}$ \\
\hline $1599-1620$ & 0 & 68 & 26 & 4 & 7 & $\mathbf{2 1}$ \\
\hline $1621-1665$ & 0 & 68 & 12 & 7 & 6 & $\mathbf{1 9}$ \\
\hline $1666-1700$ & 0 & 59 & 3 & 8 & 3 & $\mathbf{1 5}$ \\
\hline $1701-1745$ & 3 & 57 & 21 & 11 & 20 & $\mathbf{2 2}$ \\
\hline $1746-1759$ & 17 & 73 & 9 & 9 & 71 & $\mathbf{3 6}$ \\
\hline $1760-1788$ & 9 & 71 & 8 & 14 & 70 & $\mathbf{3 4}$ \\
\hline $1789-1799$ & 20 & 74 & 5 & 10 & 40 & $\mathbf{3 0}$ \\
\hline MEDIA & $\mathbf{5}$ & $\mathbf{6 4}$ & $\mathbf{1 5}$ & $\mathbf{8}$ & $\mathbf{2 5}$ & \\
\hline
\end{tabular}


LA ALTA NOBLEZA Y EL PODER EN EL ESTADO DURANTE EL ANTIGUO RÉGIMEN...

TABLA 56. Presencia media del clero en los centros de poder. Resumen final (presencia en \%. Se excluyen los cargos militares y eclesiásticos).

\begin{tabular}{|c|c|c|c|c|c|c|}
\hline Periodo & $\begin{array}{c}\text { Alta } \\
\text { Burocracia }\end{array}$ & $\begin{array}{c}\text { Gobiernos } \\
\text { provinciales }\end{array}$ & $\begin{array}{c}\text { Corregidores } \\
\text { Intendentes }\end{array}$ & Embajadores & Virreyes & Media \\
\hline $1500-1515$ & 81 & 8 & 0 & 25 & 31 & $\mathbf{2 9}$ \\
\hline $1516-1555$ & 72 & 2 & 1 & 17 & 14 & $\mathbf{2 1}$ \\
\hline $1556-1598$ & 53 & 0 & 0 & 18 & 10 & $\mathbf{1 6}$ \\
\hline $1599-1620$ & 54 & 0 & 0 & 4 & 29 & $\mathbf{1 7}$ \\
\hline $1621-1665$ & 47 & 2 & 0 & 9 & 18 & $\mathbf{1 5}$ \\
\hline $1666-1700$ & 27 & 3 & 0 & 10 & 9 & $\mathbf{1 0}$ \\
\hline $1701-1745$ & 17 & 1 & 0 & 11 & 16 & $\mathbf{9}$ \\
\hline $1746-1759$ & 18 & 0 & 0 & 6 & 14 & $\mathbf{8}$ \\
\hline $1760-1788$ & 8 & 0 & 0 & 0 & 4 & $\mathbf{2}$ \\
\hline $1789-1799$ & 11 & 0 & 0 & 0 & 0 & $\mathbf{2}$ \\
\hline MEDIA & $\mathbf{3 9}$ & $\mathbf{1}$ & $\mathbf{0}$ & $\mathbf{1 0}$ & $\mathbf{1 4}$ & \\
\hline
\end{tabular}

TABLA 57. Presencia media de la alta nobleza en los centros de poder. Resumen final comparable (presencia en \%. Se excluyen los cargos militares y eclesiásticos).

\begin{tabular}{|l|c|c|c|c|c|c|}
\hline \multicolumn{1}{|c|}{ Periodo } & $\begin{array}{c}\text { Alta } \\
\text { Burocracia }\end{array}$ & $\begin{array}{c}\text { Gobiernos } \\
\text { provinciales }\end{array}$ & $\begin{array}{c}\text { Corregidores } \\
\text { Intendentes }\end{array}$ & Embajadores & Virreyes & Media \\
\hline $1500-1515$ & 4 & 17 & 18 & 12 & 42 & $\mathbf{1 7}$ \\
\hline $1516-1555$ & 10 & 34 & 14 & 43 & 62 & $\mathbf{3 3}$ \\
\hline $1556-1598$ & 8 & 29 & 23 & 29 & 67 & $\mathbf{2 9}$ \\
\hline $1599-1620$ & 23 & 33 & 34 & 82 & 64 & $\mathbf{4 7}$ \\
\hline $1621-1665$ & 24 & 34 & 34 & 69 & 72 & $\mathbf{4 7}$ \\
\hline $1666-1700$ & 24 & 41 & 50 & 68 & 84 & $\mathbf{5 3}$ \\
\hline $1701-1745$ & 21 & 36 & 32 & 51 & 57 & $\mathbf{3 9}$ \\
\hline $1746-1759$ & 26 & 19 & 34 & 54 & 14 & $\mathbf{2 9}$ \\
\hline $1760-1788$ & 24 & 24 & 10 & 43 & 26 & $\mathbf{2 5}$ \\
\hline $1789-1799$ & 12 & 27 & 33 & 23 & 40 & $\mathbf{2 7}$ \\
\hline MEDIA & $\mathbf{1 8}$ & $\mathbf{2 8}$ & $\mathbf{2 8}$ & $\mathbf{4 8}$ & $\mathbf{5 3}$ & \\
\hline
\end{tabular}


Tabla 58. Tabla comparativa final. Presencia media de cada grupo en el conjunto de los cargos. Por reinados ${ }^{72}$.

\begin{tabular}{|l|c|c|c|c|}
\hline \multicolumn{1}{|c|}{ Periodo } & ALTA NOBLEZA & CLERO & MILITARES & BURÓCRATAS \\
\hline $1500-1515$ & 17 & 29 & 17 & $\mathbf{3 4}$ \\
\hline $1516-1555$ & 33 & 21 & 22 & $\mathbf{2 5}$ \\
\hline $1556-1598$ & 29 & 16 & 17 & $\mathbf{3 4}$ \\
\hline Siglo XVI & $\mathbf{2 6}$ & $\mathbf{2 2}$ & $\mathbf{1 9}$ & $\mathbf{3 1}$ \\
\hline $1599-1620$ & 47 & 17 & 21 & $\mathbf{1 5}$ \\
\hline $1621-1665$ & 47 & 15 & 19 & $\mathbf{1 9}$ \\
\hline $1666-1700$ & 53 & 10 & 15 & $\mathbf{2 4}$ \\
\hline Siglo XVII & $\mathbf{4 9}$ & $\mathbf{1 4}$ & $\mathbf{1 8}$ & $\mathbf{1 9}$ \\
\hline $1701-1745$ & 39 & 9 & 22 & $\mathbf{2 7}$ \\
\hline $1746-1759$ & 29 & 8 & 36 & $\mathbf{2 5}$ \\
\hline $1760-1788$ & 25 & 2 & 34 & $\mathbf{3 7}$ \\
\hline $1789-1799$ & 27 & 2 & 30 & $\mathbf{4 2}$ \\
\hline Siglo XVIII & $\mathbf{3 0}$ & $\mathbf{5}$ & $\mathbf{3 0}$ & $\mathbf{3 3}$ \\
\hline MEDIA & $\mathbf{3 5}$ & $\mathbf{1 3}$ & $\mathbf{2 3}$ & $\mathbf{2 8}$ \\
\hline
\end{tabular}

TABla 59. Tabla comparativa final. Presencia media de cada grupo en los distintos cargos (ss. XVI-XVIII, en \%).

\begin{tabular}{|l|c|c|c|c|c|}
\hline & $\begin{array}{c}\text { Alta } \\
\text { Burocracia }\end{array}$ & $\begin{array}{c}\text { Gobiernos } \\
\text { provinciales }\end{array}$ & $\begin{array}{c}\text { Corregidores } \\
\text { Intendentes }\end{array}$ & Embajadores & Virreyes \\
\hline ALTA NOBLEZA & 18 & 28 & 28 & 48 & 53 \\
\hline BURÓCRATAS & 37 & 8 & 56 & 33 & 7 \\
\hline MILITARES & 5 & 64 & 15 & 8 & 25 \\
\hline CLERO & 39 & 1 & 0 & 10 & 14 \\
\hline
\end{tabular}

72. Se han excluido los cargos eclesiásticos, porque las fuentes no permiten precisar su origen social, y los militares, dado que a éstos últimos ni los burócratas ni los clérigos tenían acceso y no había por tanto competencia entre todos los grupos. 


\section{Conclusiones}

1. Aumento del poder político de los burócratas, mayoritariamente graduados universitarios, a lo largo del siglo XVI, debido fundamentalmente al crecimiento del entramado burocrático y a la reserva de plazas para licenciados en derecho

2. Aumento del poder político de la alta nobleza a lo largo de los siglos $\mathrm{XVI}$-exceptuando el reinado de Felipe II- y XVII, a costa fundamentalmente del clero en el siglo XVI (su presencia cae de un $29 \%$ a un $16 \%$ de los cargos a lo largo del siglo) y de los burócratas en el XVII (su presencia cae de un 31\% de los cargos en el XVI a un $19 \%$ entre 1599 y 1700)

3. Caída paulatina del poder del clero, hasta prácticamente desaparecer en la segunda mitad del siglo XVIII (22\% de los cargos en el XVI, 14\% en el XVII y $5 \%$ en el siglo XVIII)

4. Aumento del poder de los militares a partir de mediados del siglo XVIII, a costa fundamentalmente de la alta nobleza y del clero (19\% de los cargos entre 1500 y 1745 , frente a un $33 \%$ entre 1746 y 1799)

5. Recuperación del poder de los burócratas a partir de mediados del siglo XVIII, a costa fundamentalmente de la alta nobleza y del clero (pasan de ocupar un $22 \%$ de los cargos entre 1599 y 1745 a un $39 \%$ entre 1746 y 1799)

6. Caída del poder de la nobleza a lo largo del siglo XVIII (un 49\% de los cargos en el siglo XVII, frente al $27 \%$ en la segunda mitad del XVIII)

7. Pérdida del control de los linajes nobiliarios procedentes de la Edad Media sobre los mecanismos de acceso al grupo a partir del reinado de Carlos II (hasta este momento controlaron, como mínimo, un $80 \%$ de las designaciones, pasando a controlar menos de un $20 \%$ en la segunda fase), pero conservando las Grandezas de España como criterio distintivo de estas familias, aunque con poca claridad en el siglo XVIII. Las élites locales, de donde proceden el grueso de los burócratas y buena parte de los militares de alto rango, son el grupo social que se beneficiará de este proceso. 